Vol. 16 , No, 61 ,October2021, 1313-1329

\title{
BIM FOR DOCUMENTING ISLAMIC ARCHITECTURAL ELEMENTS (ARCHES, FATIMY POINTED ARCHES)
}

\author{
Hani El.Gharib Ibrahim Youssef ${ }^{1}$, Hani Sa`ad Salim Ahmad ${ }^{2}$, Mohammad Hassan Khalil ${ }^{2}$ \\ ${ }^{1}$ BIM Manager, Freyssinet Saudi Arabia, KSA. \\ ${ }^{2}$ Architecture Engineering Department, Al-Azhar University, Egypt, Cairo. \\ Corresponding author's E-mail: architect.Hani@gmail.com
}

\begin{abstract}
Received :21 August 2021 Accepted: 10 September 2021

Heritage is the real show of human life and culture. The architectural heritage in the overall sense is the material heritage that contains a cultural, artistic and creative aesthetic or functional value, and reflects the origins and rules which a civilization was built on, and how the perceptions of its societies and what was its philosophy in the measures of their sciences and coexistence. Therefore, this legacy of the ancestors needs to those who reconsider it and its importance, by spotting light on the problems that threaten its continuity. This will only come by encompassing all its components, and also reviewing how it can make it one of the foundations for achieving sustainable development, and one of the poles of the economy by integrating it into the core of its concerns Progressive programs, projects and technology that the state is betting on achieving.

Therefore, this research paper focuses on finding a methodology for the documentation processes related to the vocabulary of Islamic elements (Arches and the use of some vocabulary as a model for applying that Technology), starting with defining the architectural style and the optimal way to preserve information and add data so that these vocabulary can be used to facilitate the preservation and development processes for many Buildings of heritage Islamic architecture, in particular, in addition to the general interest for scholars and those interested in the vocabulary of architectural heritage, as well as extracting architectural drawings from Plans, facades, Sections, quantities, Schedules, etc., for all architectural and construction requirements.
\end{abstract}

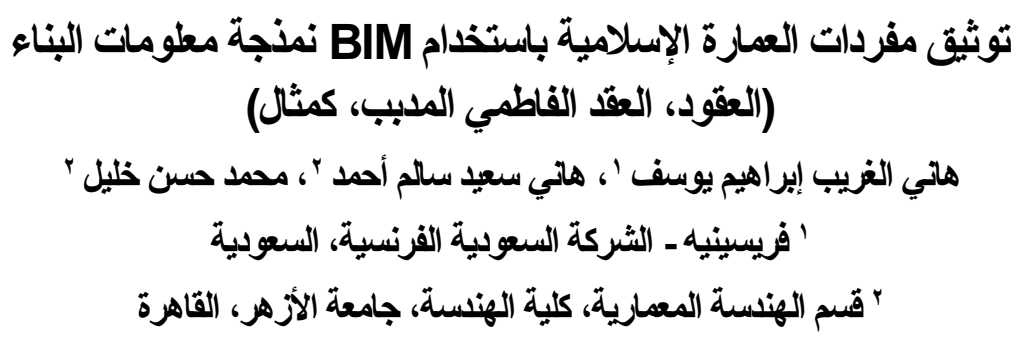




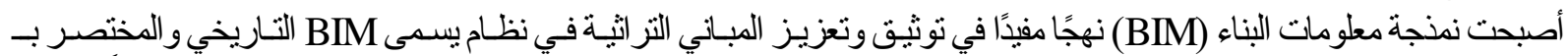
هeritage Building Information Modeling (HBIM)

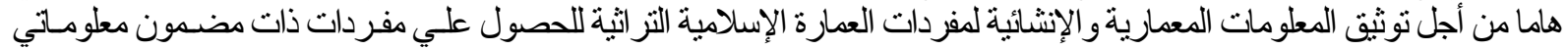

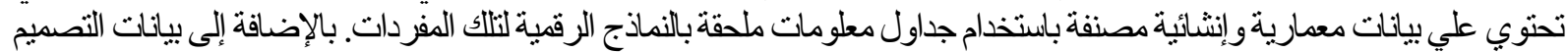

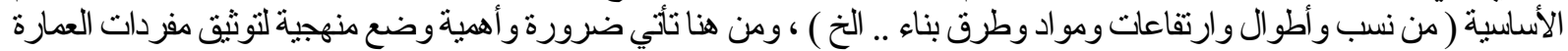

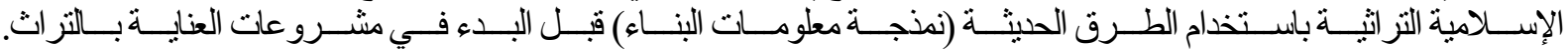

لذا تركز هذه الورقة البحثية على إيجاد منهجية لعمليات التوثيق الخاصة بمفردات العناصر الإسلامية، (العقود واستخدام بعض المئو المفردات

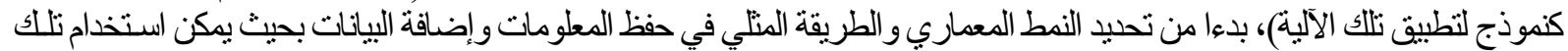

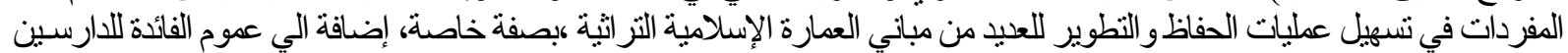

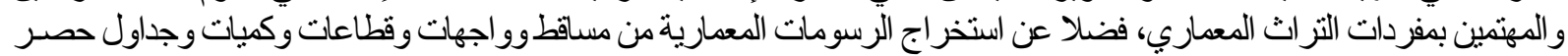
اعمال .. الخ من كافة المتطلبات المعمارية والإلثمائية.

الكلمات المفتاحية

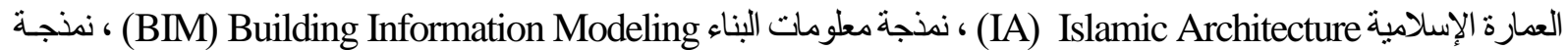

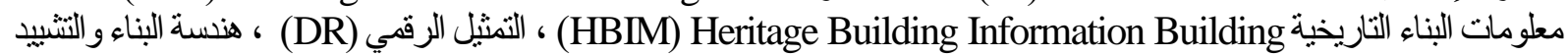
(LOD) Level Of Details الرفي ، (AEC)Architecture Engineering Construction

مقدمة

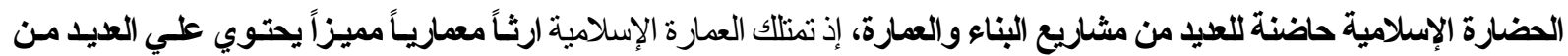

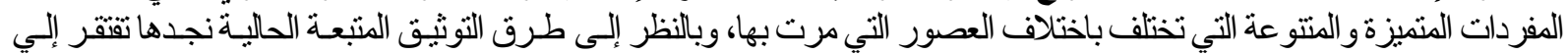
النطوير.

على مدار الثلاثثن عائًا الماضية، ناريخ نشأة BIM، اقتصرت معظم أعمال نمذجة معلومات البناء BIM المباء

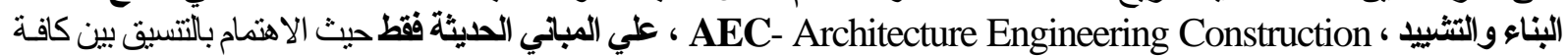

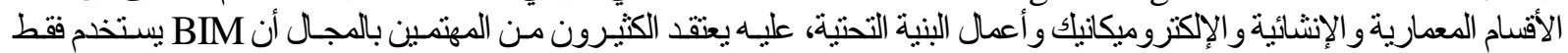
لتصميم المباني أوتخطيط الدن الجديدة ، وإنما ينبغي استخدام BIM في العصر الحالي كأداة لنمنجة وإضافة المطومات للمبلني التراثيـة

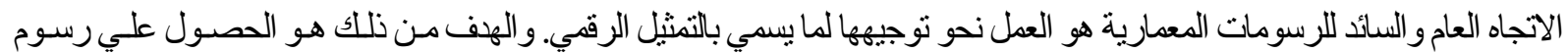

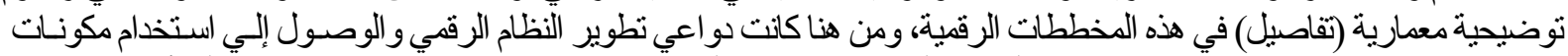

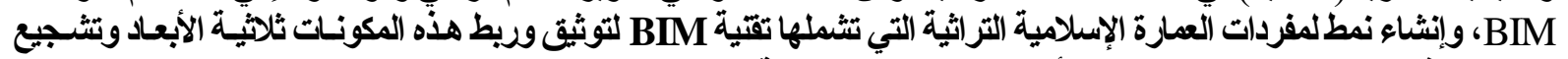

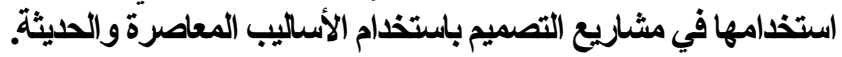

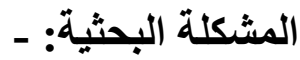

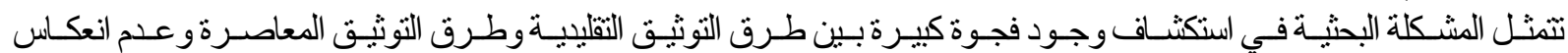

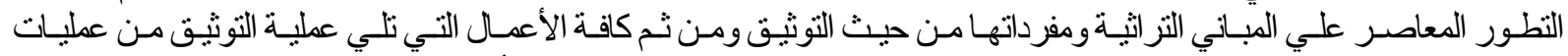

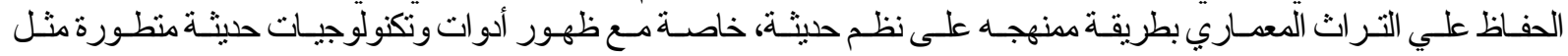

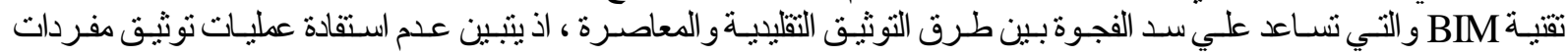

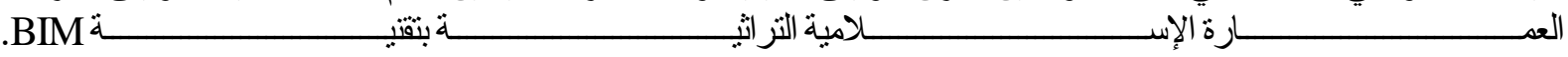

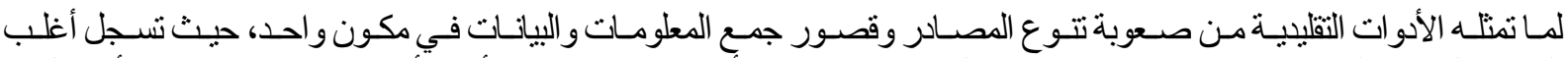

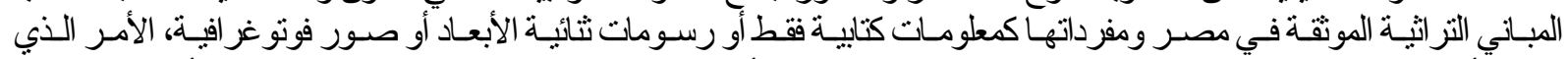

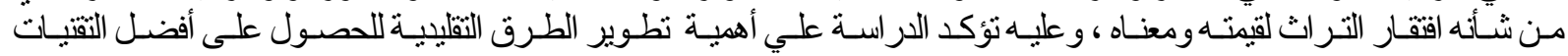
حفاظا على التزراث المعماري في مصر. 


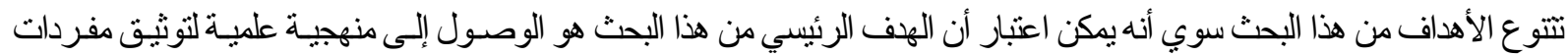

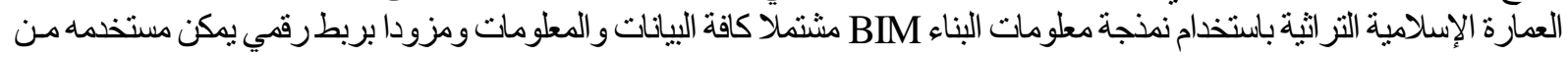

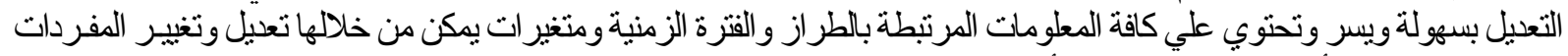

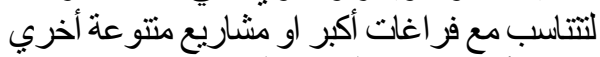

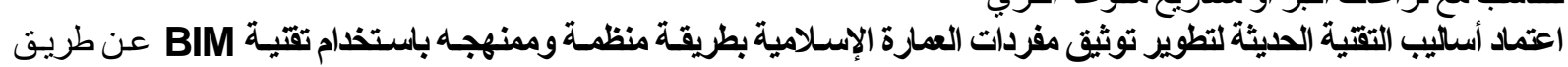

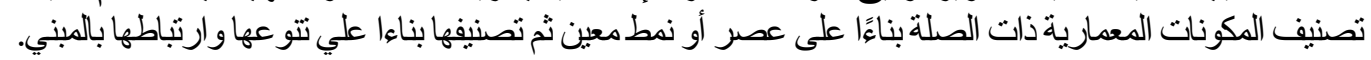

فرضية البحث البحت

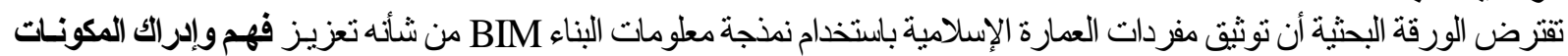

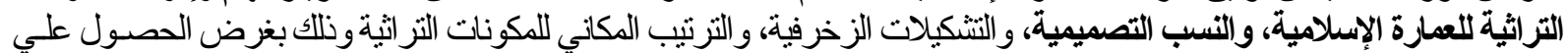

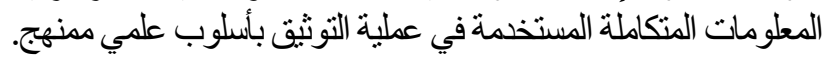

\section{يعتمد المنهج البحثي لهذه الورقة البحثية على: -}

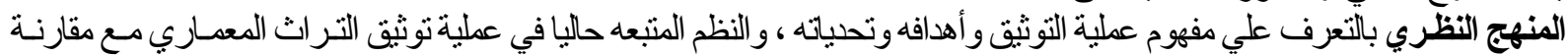

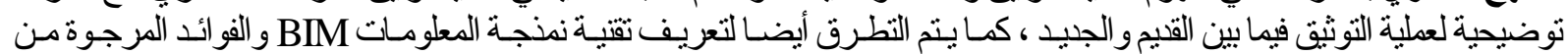

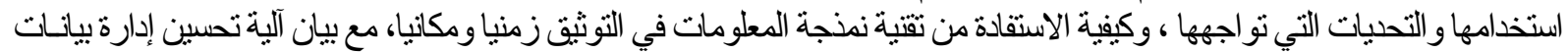

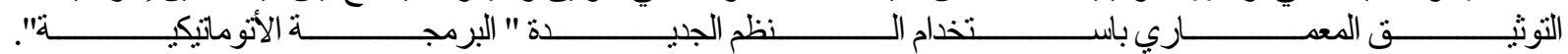

المنهج التطيقي تطييق الحلول و التقنيات المستخمة في BIM علي مفردات العمارة الإسلامية لتحليد الوضع القائم في توثيق العقود المديبة

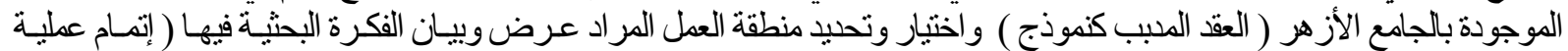

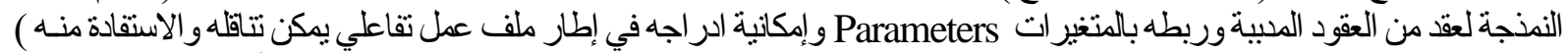

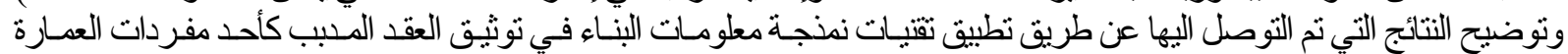

الإسلامية التنز اثنية.

الار اسات السبابقة

تنو عت الدرسات السابقة في النطاقات المختلفة للمباني التزا اثية بدءا من تحرير العناصر من أجل الحصول على نظام فهرسة وتصنيف قائم

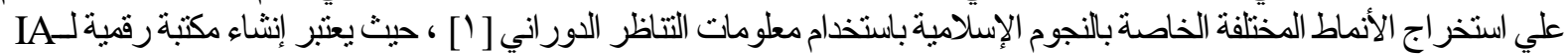
أحد أهم الطرق التي تساعد في تمكين فهم أفضل لـ IA Islamic Architecture

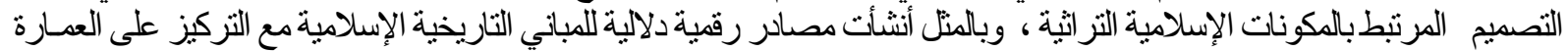

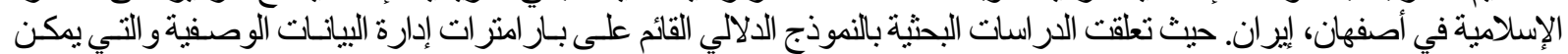

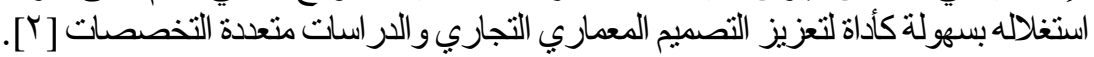

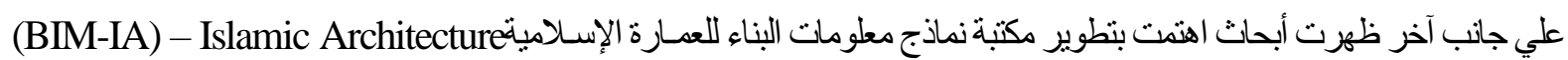

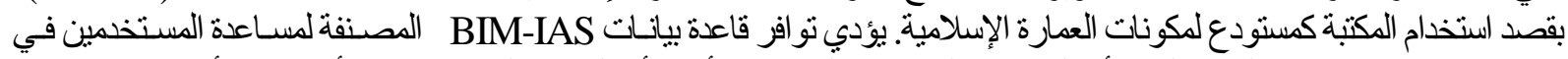

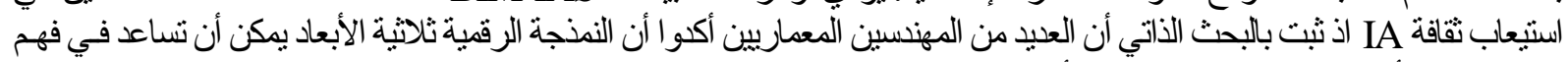

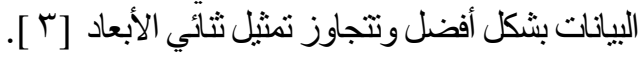

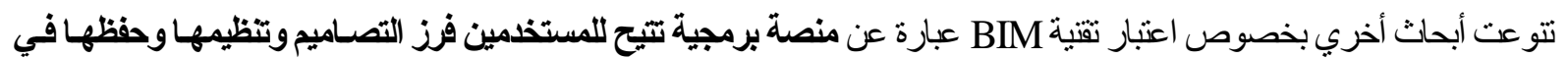

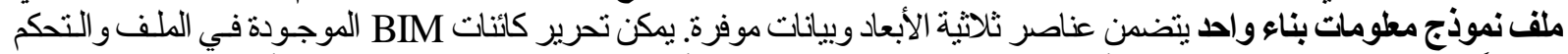

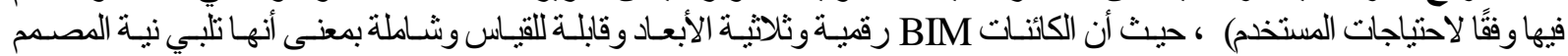

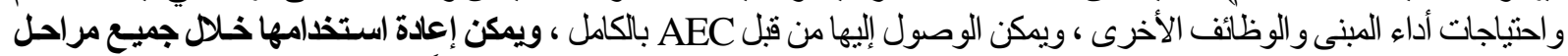

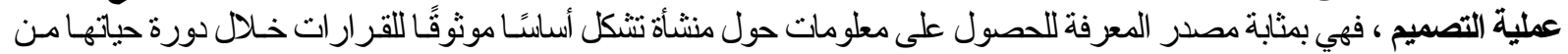

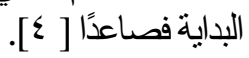

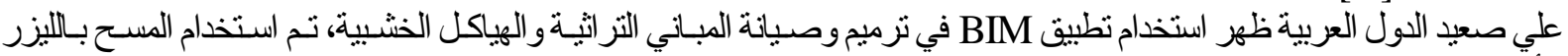

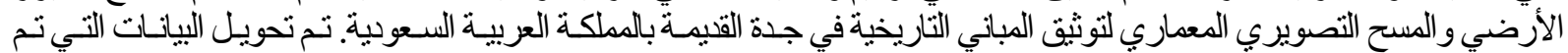

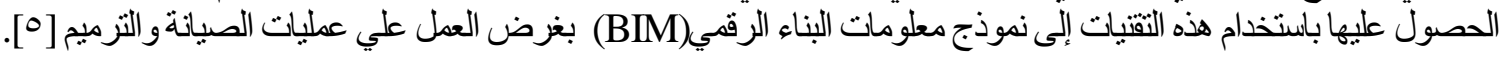

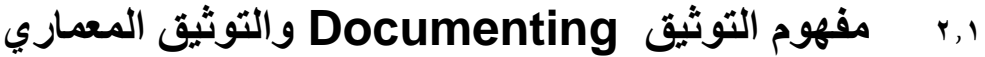

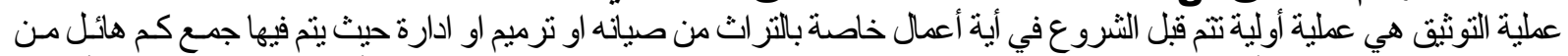

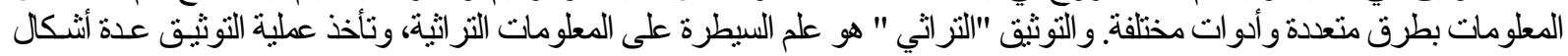




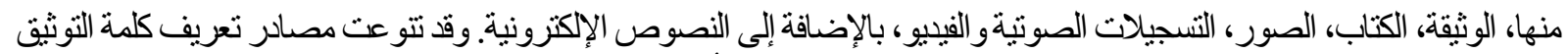

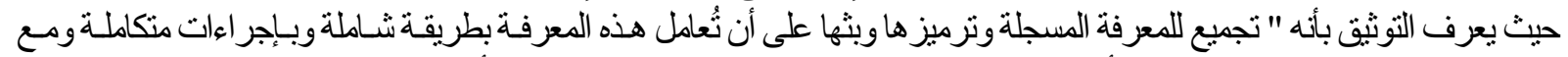

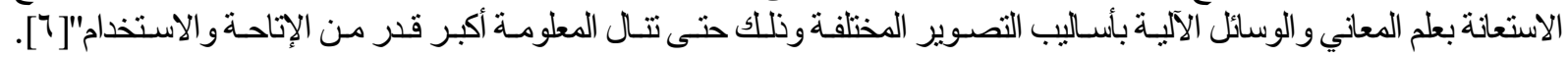

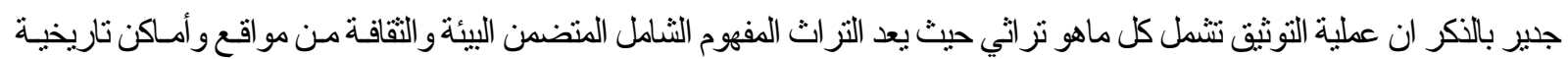

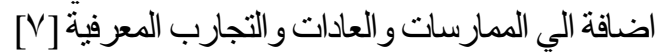

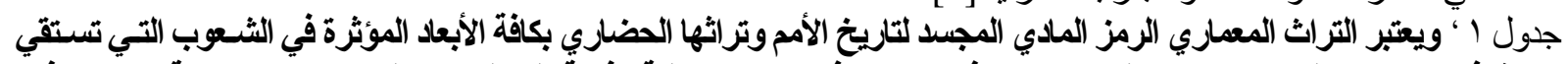

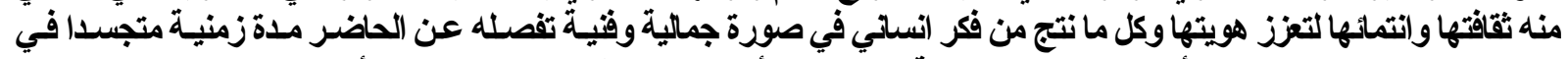

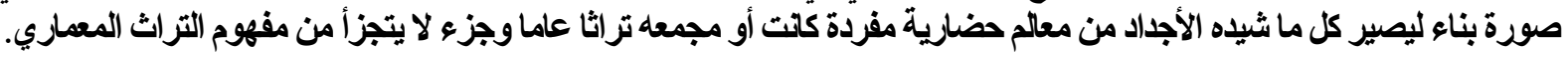

\begin{tabular}{|c|c|}
\hline التعربف & المفهوم \\
\hline 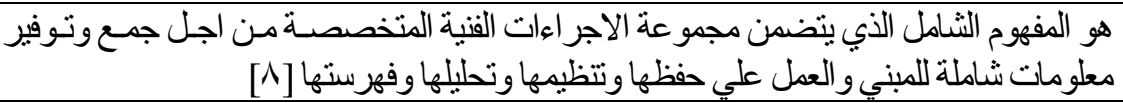 & التوثيق \\
\hline 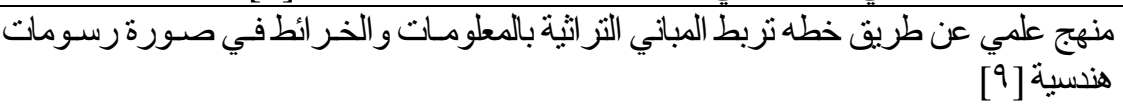 & 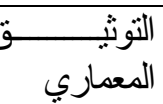 \\
\hline
\end{tabular}

r, r أهداف عملية التوثيق المعماري

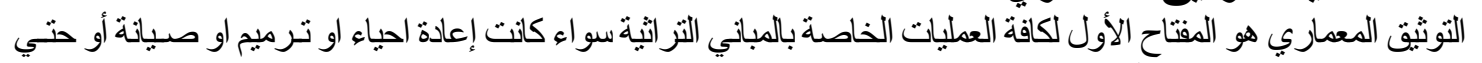
هدم حيث يتم توفير قاعدة معلومات يتم الإستفادة منها .

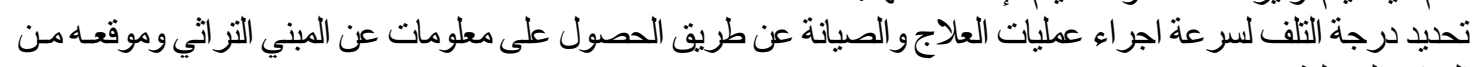
البيئات المختلفة • وضع استر اتيجية للحفاظو الصيانة الدائمة للمبني التراثي، حيث يعد التوثيث حماية للمرمم عن أدائه فى عمليات الترميح.

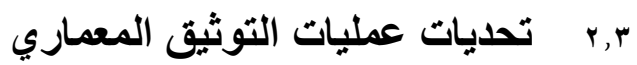

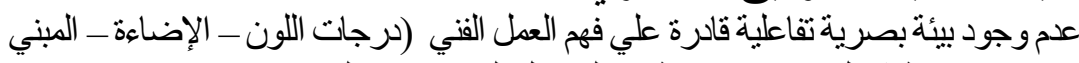

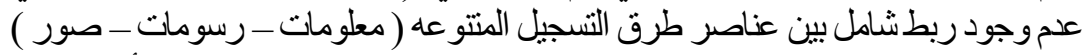

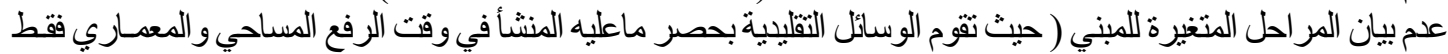
EXISTING

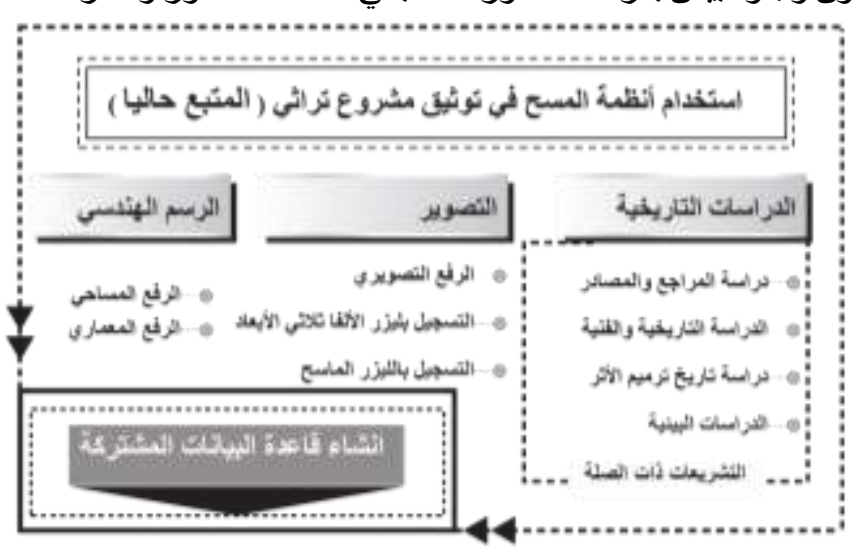

بالي:-

الاسراست التاريخية للمبني الأثري حيث ابراز الأهميـة التاريخية.

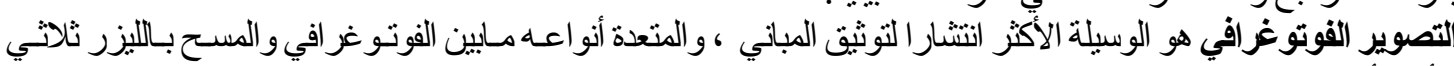
الرسم الهنسبي ويشمل اعداد الرسومات و القياسات الميدانية ، بما في نلك الارتفاعات و المقاطع و التفاصبل

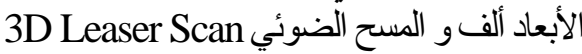

\section{؛, الن النظم المتبعة حاليا في عملية التوثيق المعماري}

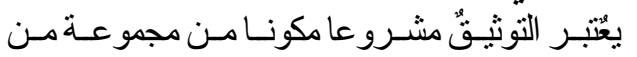

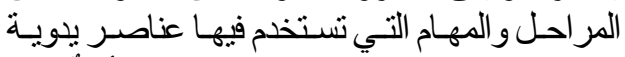

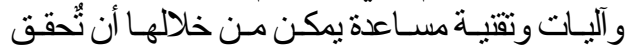

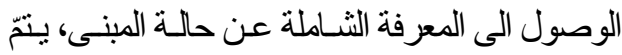

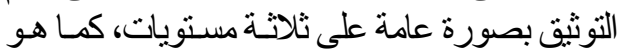

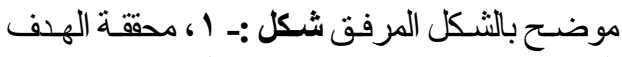

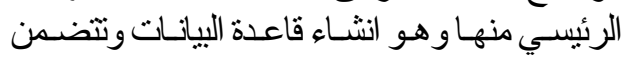

$$
\text { شكل :- } 1 \text { النظم المتبعه حاليا في عملية التوثيق المعماري }
$$

بلر اسة المر اجع والمصادر اضافة الي الدراسات البيئية. JAUES, 16, 61 , 2021 


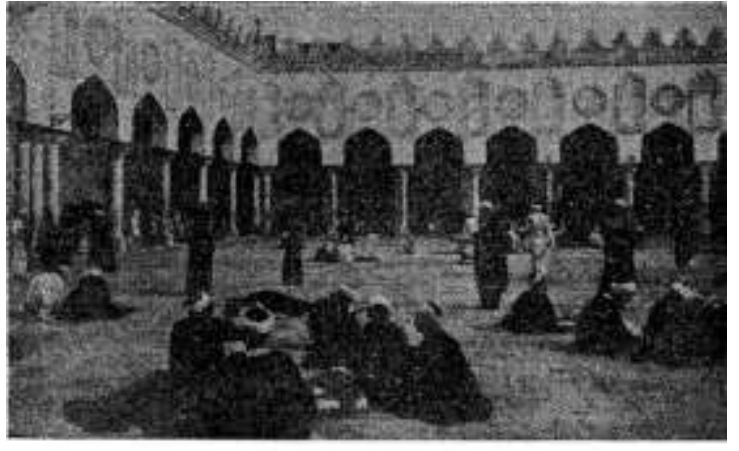

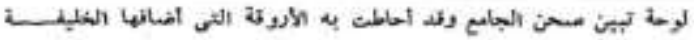

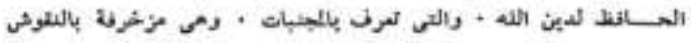

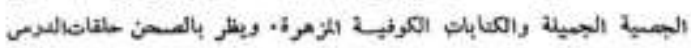

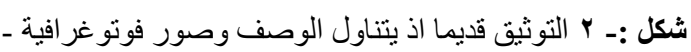
المصدر الأزهر أثثر وثقافة ـ د. سعاد ماهر

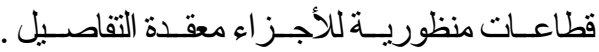
حفظ الاثار العربية الكثير من الثواهد اهد في هذا الأمـر

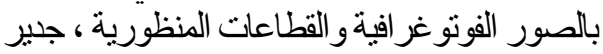

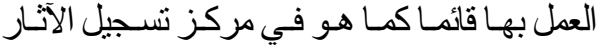

يينما نتناول الاعمال الحالية عملية رسم مجرد حيـ

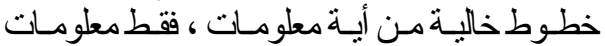
أساليب التوثيث الحالية الي توفير السبل ذابلة ذات الحفـاظ

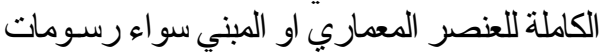

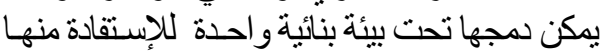

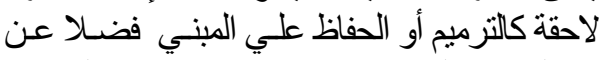

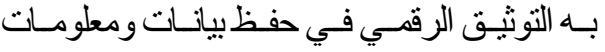

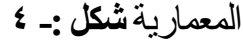

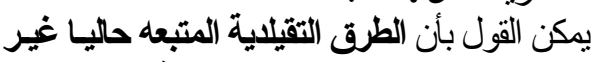

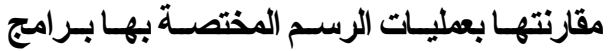

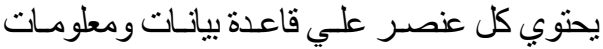

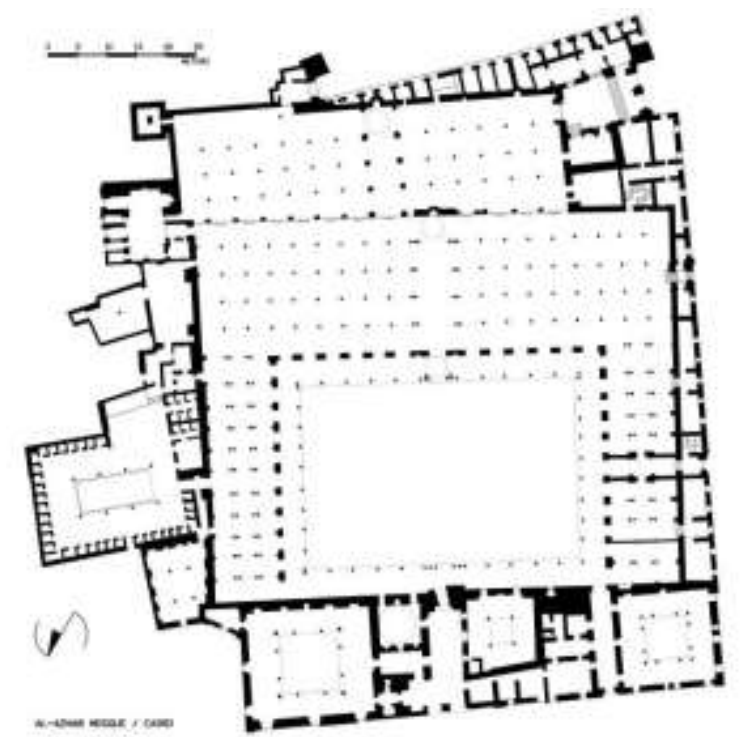

فيما بعد تثم إضافة أعمال التوثيق المعماري للمبني من مساقط أفقية وو اجهات

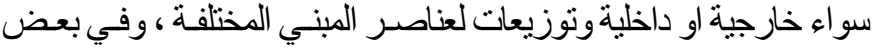

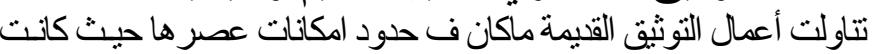

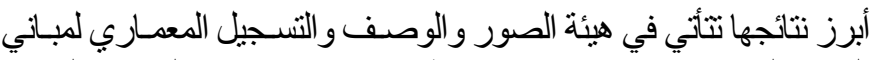

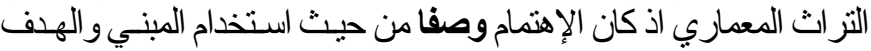

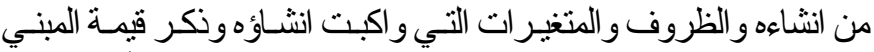

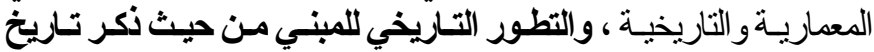

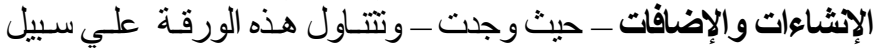

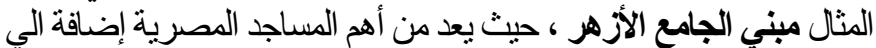

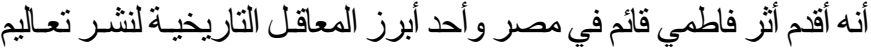

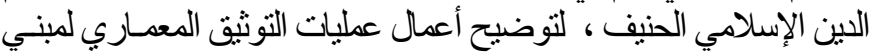

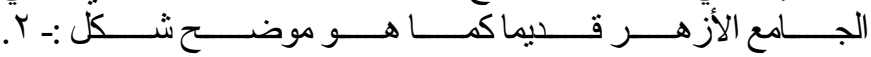

خاصة بها متضمنة تر ابط بار امتري مع كل مكونات العنصر ارتباطاوثيقا بحيث لايمكن التعديل في أحدهم دون الآخر اذ تعتبر المكونـات

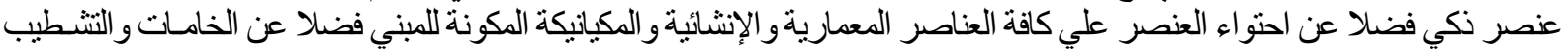

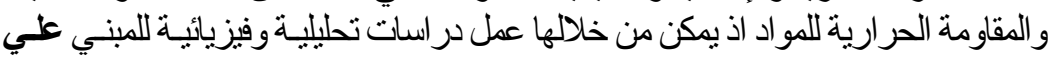

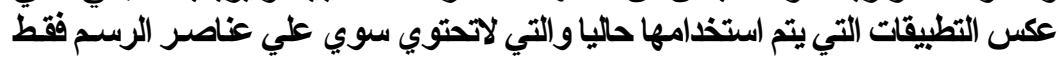

شكل :- ب من أعمال مركز تسجيل الاثار الإسلامية التابع لوزارة السياحة و الآثار بالقلعة الآنال

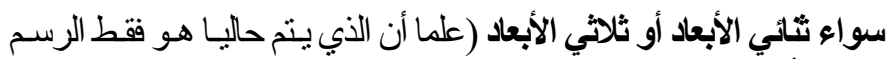

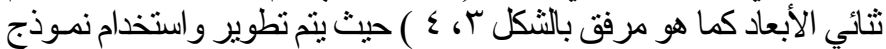

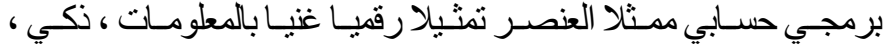

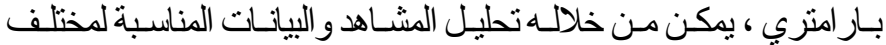
الاحتياجات والتخصصات بحيث بمكن استعمالها لاتخـاذ قرار ات وتحسين

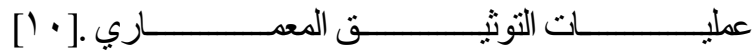

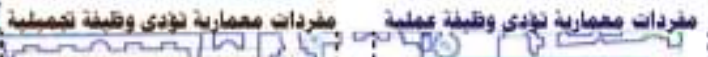
المئرنصاك

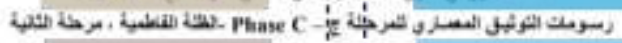

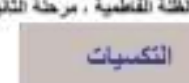

\section{الثقوش}

الزخخزف الفطوط
القباب

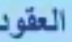
الصحن المبرداب
شكل :- ؛ التوثيق المعماري و الرفع المساحي للجامع الأزهٍُ

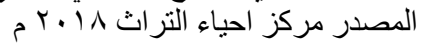

\section{r, r مفردات العمارة الإسلامية} المفردات المعمارية الإسلامية على مدى تعاقب الفترات وبعد المكان ذات ذات الماته هيئة متكاملة، حيث تجمع بين الوظيفة والفن الجمالي المتميز معا كتعبير JAUES, 16, 61 , 2021 
للأصلاة التي تحتويها تلك الحضلارة، حيث تزخر العمارة الإسلامية بالعليد من الدفردات و التي تتقسم ببور ها الوظيفي إلي قسمين رئبسبين:

مفردات معمارية تؤدى وظيفة عملية

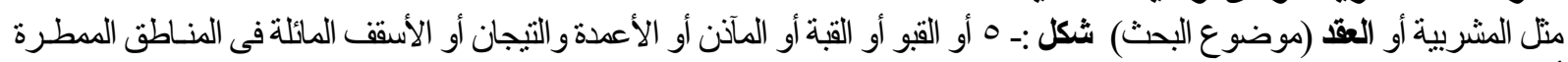
أو فى الملاقف العلوية المربعة.

مفردات تشكيلية تؤدى وظيفة تجميلية

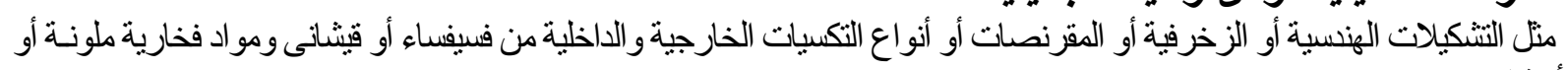
أخثاب [11) شكل :- 0 موسو عة عناصر العمارة الاسلامية ـ الجزء الثاني تأليف: يحيى وزيري الناشر : مكتبة مدبولي ـ القاهرة الطبعة : 1999 العقود في العمارة الإسلامية اسـتخمت العقود في العمـارة الإســامية كأحسد المفـردات

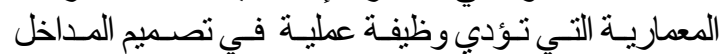
و الأعدة ، حيثّ تميزت و أبدعت عن طريقيق تكوين أشكالٍ

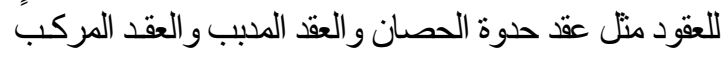

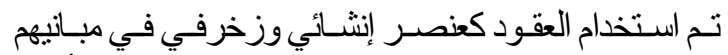

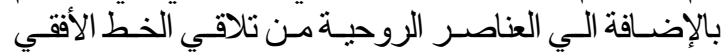
بالأرض ( المخلوق ) والخطوط الرئرأسية إلي الَّماء (الخـالق)

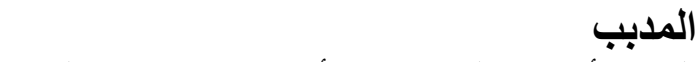
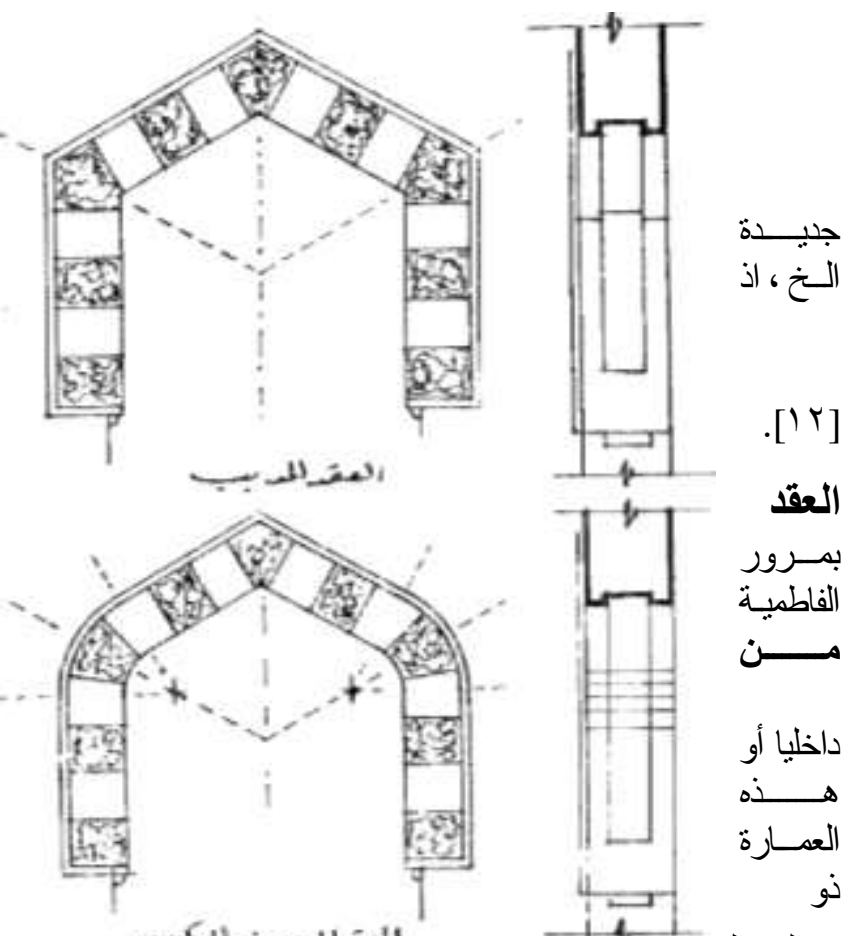
الوقت ، أصبحت العقود دعامـة أساسية تستخلم في العمارة ،حيث أصبحت أحد المكونات الفريدة التي تمثل جزعًاً أساسيًاً

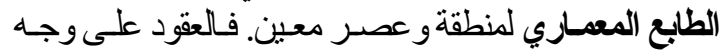

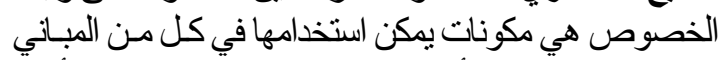

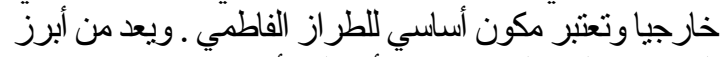

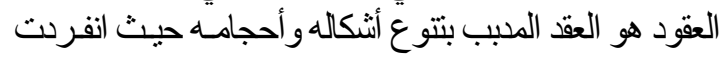

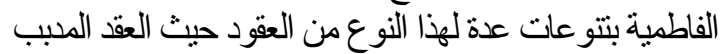

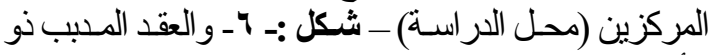

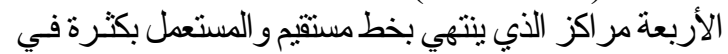

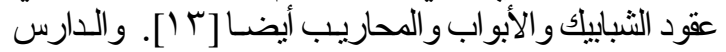

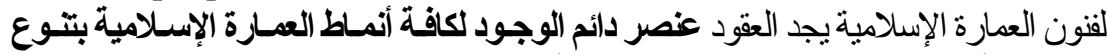

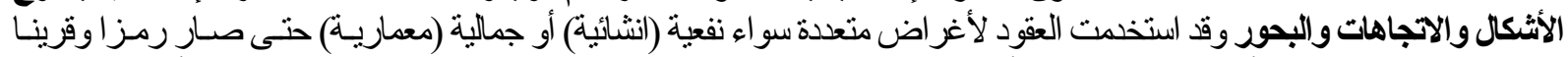

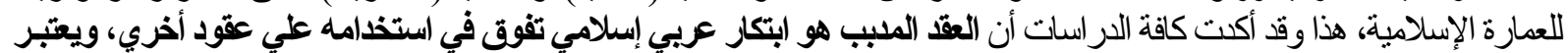

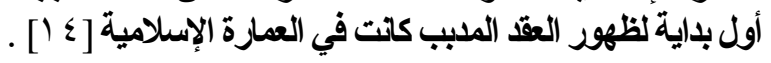

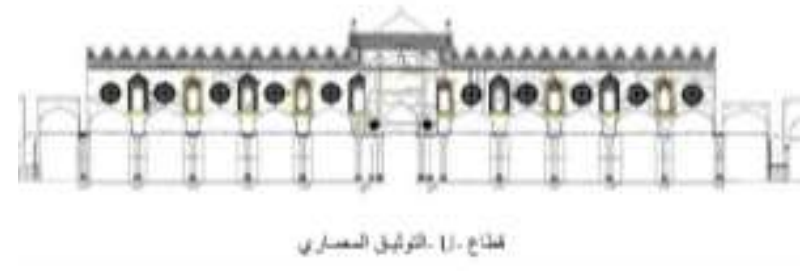

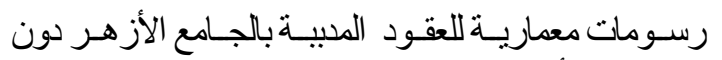

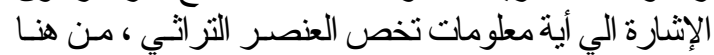

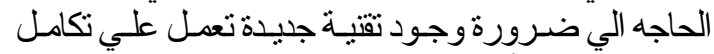

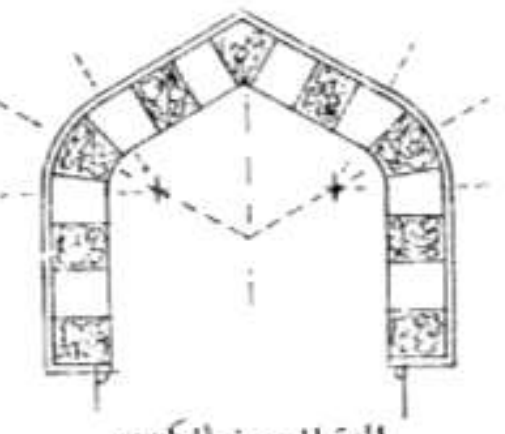
دراسات في العمارة الإسلامية (عبد السلام أحمد نظيف )

ويلاحظ أن التوتيق قليما كـان يهنت بكامـل المبنـي دون افر اد للمفردات

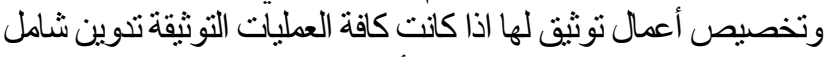

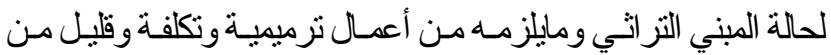

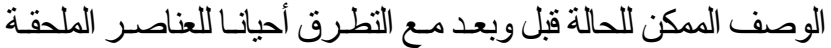

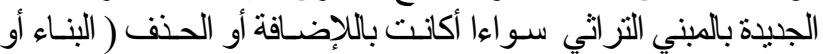

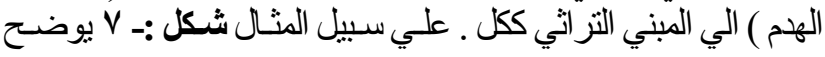

شكل :- V العقود الددببة بالجامع الأز هر و افتقار ها إلي تكامل

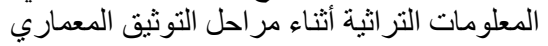
كانت جميع المعلومات اللازمة لتوثيق مفردات العمارة الإسلامية التزراثية والذي يمثل (العقد التببب) أحد هذه الكفردات. 
BIM التعريف بتقنية نمذجة معلومات البناء r,v

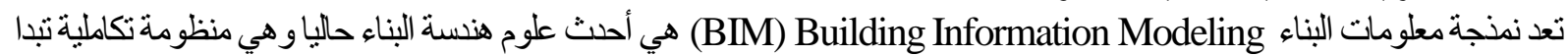

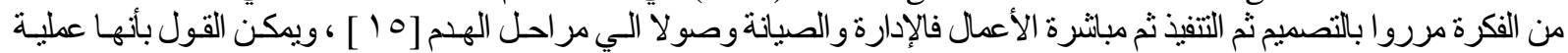

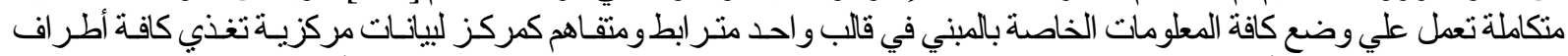

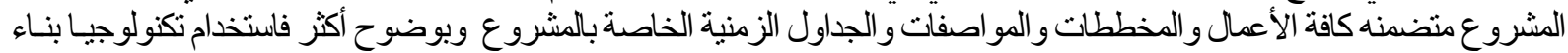

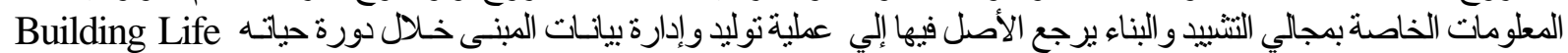

Cycle

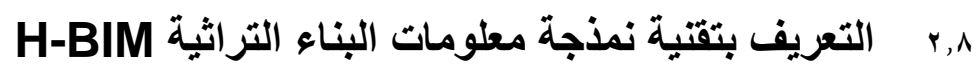

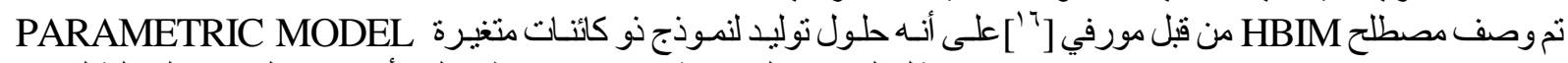
GENERATION SOLUTION

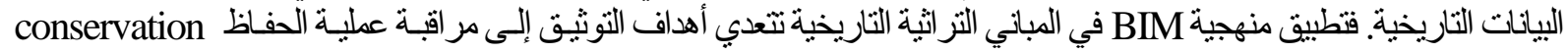

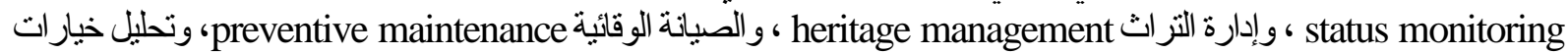
، التدخل ، وتخطيط الحفظو الاستعادة analysis of intervention options, conservation and restoration planning

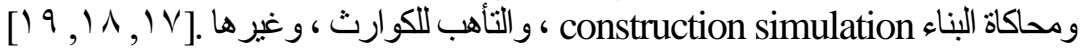

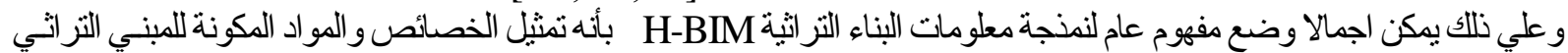

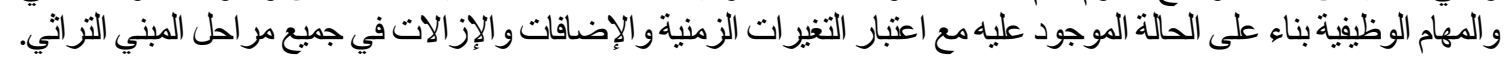

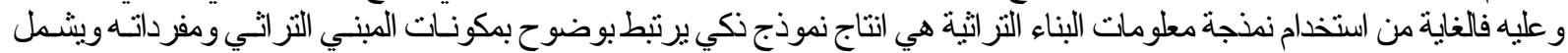

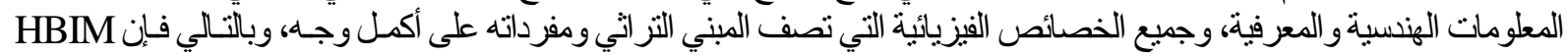

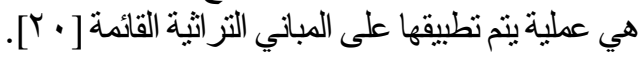

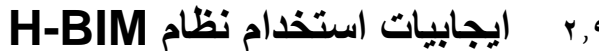 \\ تصور المعلومات ثلاثثية الأبعاد والاستفادة من القدرات التي توفرها أدوات BIM، التحليل والاستعلام ، إدارة الوقت ، المرونـة

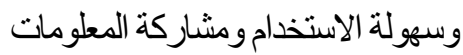

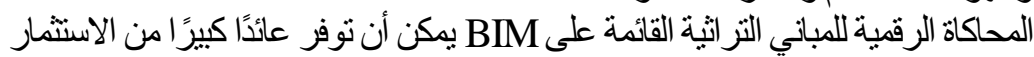

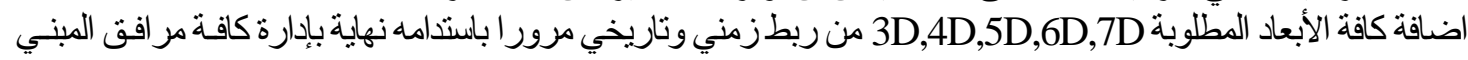
وصياتنها.

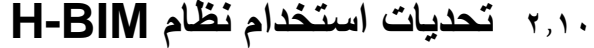
تستتد H-BIM عمومًا إلى عملية المسح الضوئي الأمر الذي يعد مكلفا الي درجة ما حاليا نظر الارتفاع أسعار هذا النوع من الأجهزة الثشروخ و التشو هات و الأمور المحيطة بالمباني التراثية ينتج عنها ملايين النقاط السحايية الإضـافية يجب تفاديها بعين الخيير

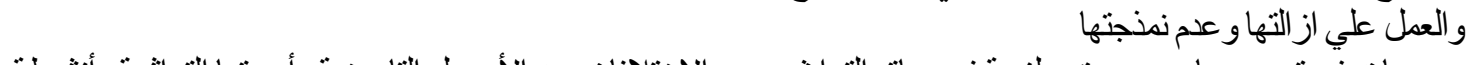
صعوبات في تحليد معليير محلدة وملزمة في سياق التزاث بسبب الاختلافات بين الأصول التاريخية وأهيتها التراثيـة وأنشطة الحفظو التوثيث المطلوبة

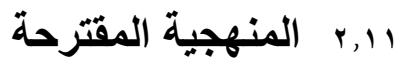

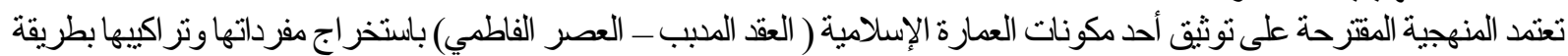

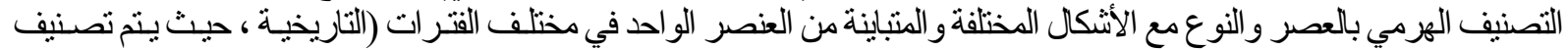

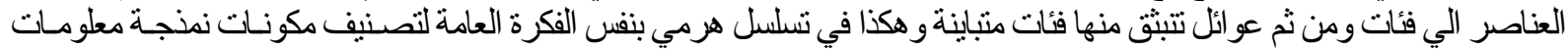

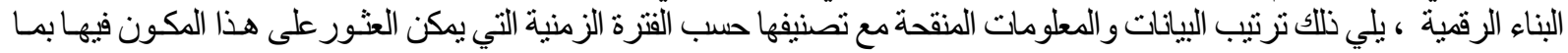

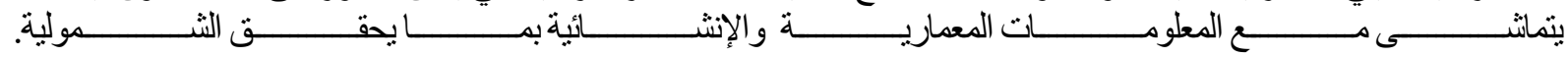

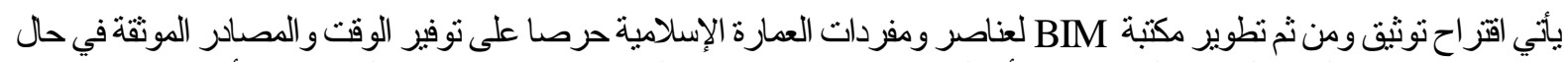

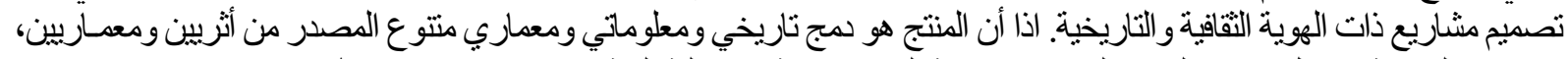

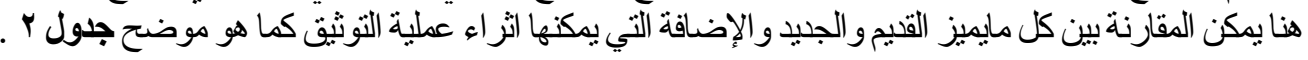




\begin{tabular}{|c|c|c|}
\hline نظام BIM & نظام CAD & امكانات \\
\hline - & घ & 2D \& 3D الرسومات \\
\hline - & & $4 \mathrm{D}, 5 \mathrm{D}, 6 \mathrm{D}, 7 \mathrm{D}$ \\
\hline घ & & الييانات التاريخية \\
\hline & - & الأخطاء التصميمية \\
\hline & 口 & تضارب المعلومات \\
\hline$\square$ & & امكانية التعديلات \\
\hline$\square$ & & تسلسل مر احل التتبييد \\
\hline & - & تعديلات يلوية \\
\hline च & & در اسات بيئية وفيزيائية \\
\hline$\square$ & & تعاون المجالات المختلفة \\
\hline
\end{tabular}

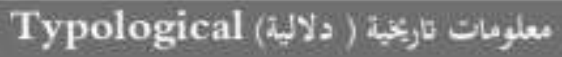

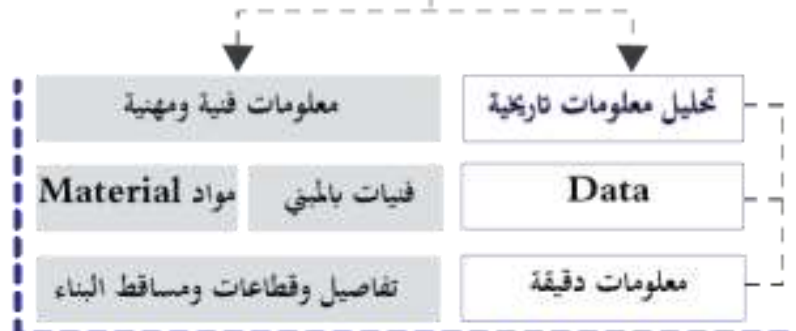

\section{Filtring الزيب رالتيلية}

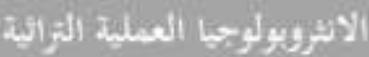

تلفيح المعلومات التاريخية ومواجعتها مع أهل الإختصاص

شكل :- ^ طريقة جمع المعلومات التناريخية الخاصة بالعناصر التراثية وترتييها وصو لا للعمل بـ BIM

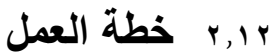

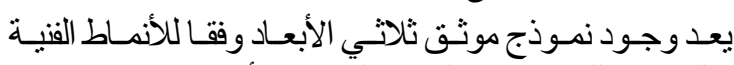

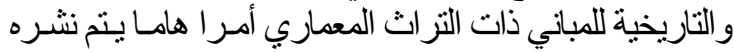

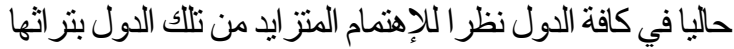

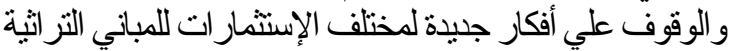

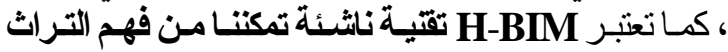

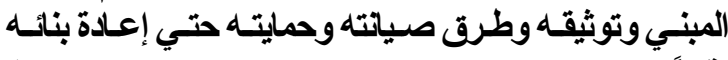

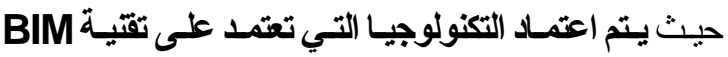

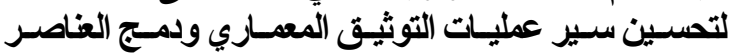

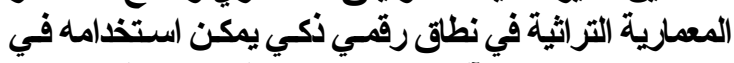

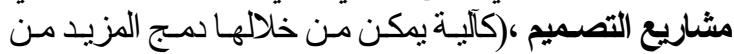

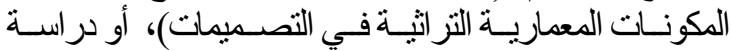

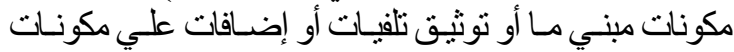

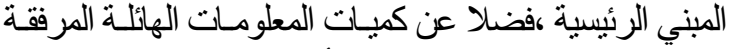

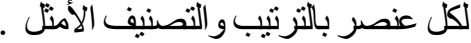

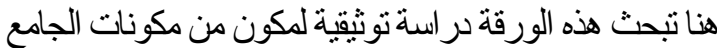
الأزهر من أجل إثبات قابلية استخدام BIM كأداة جليدة للتونئيق

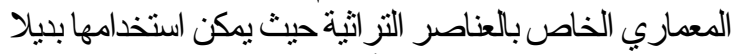

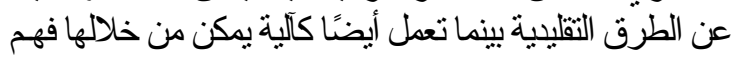

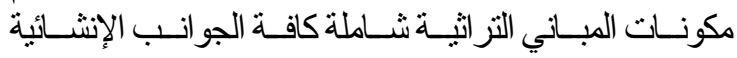

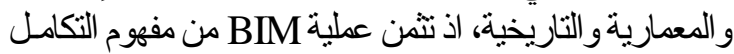

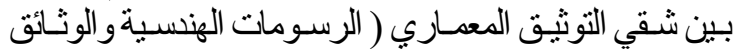

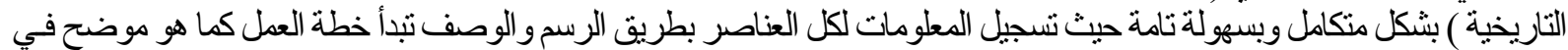

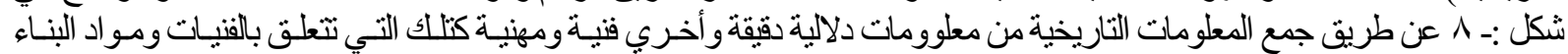

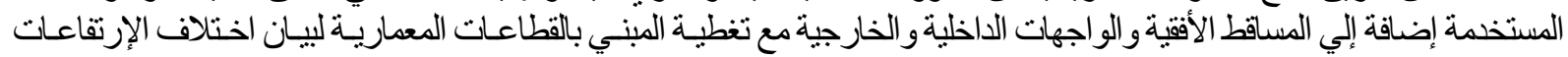




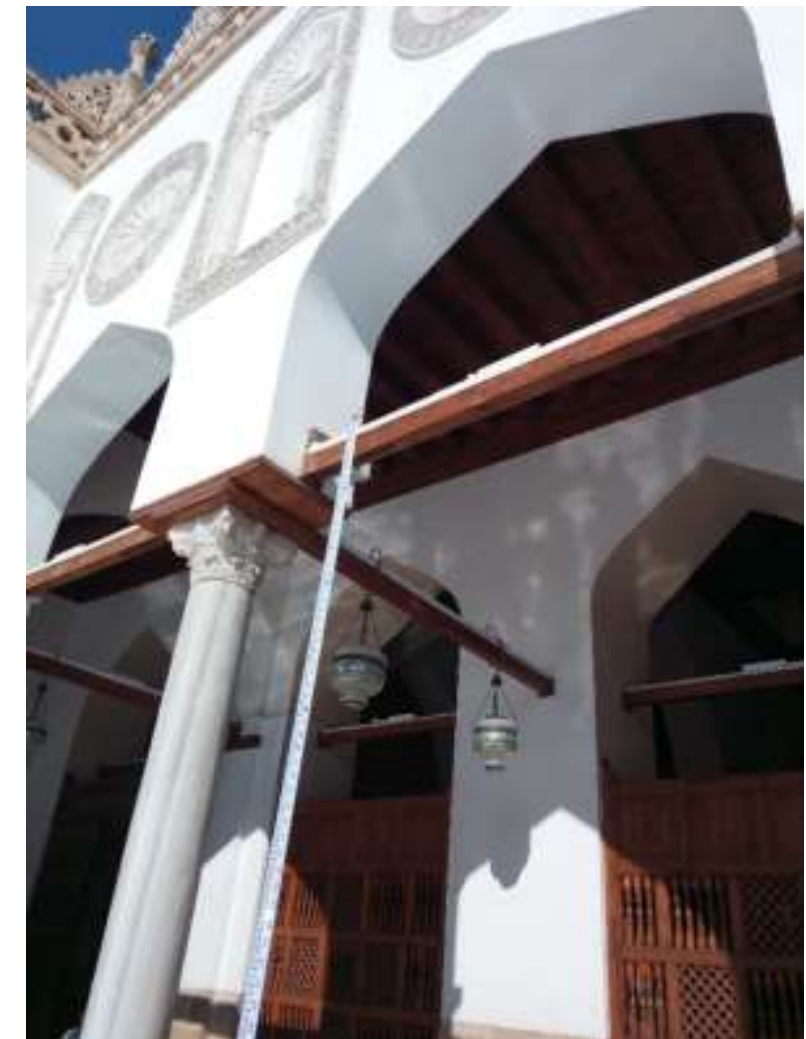

قطاع الآثار و المهنسين المعماربين إذ تبدأ بتلقي كافة المعلومات و الييانتات

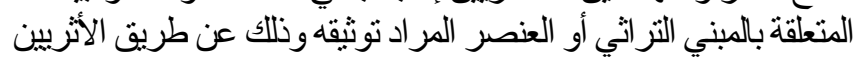
و المختصين بتسجيل العناصر التراثية.

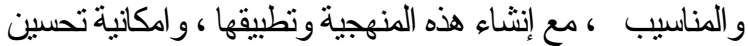

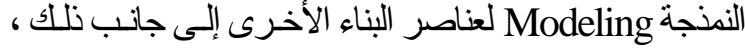

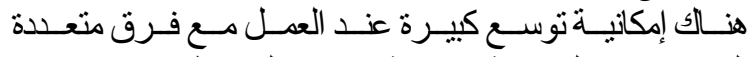

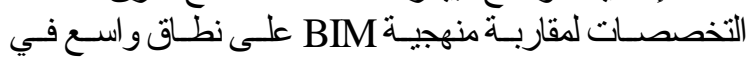

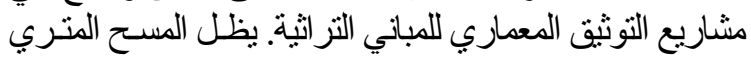

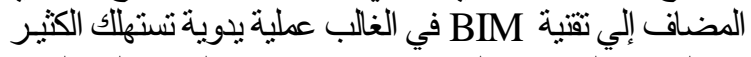

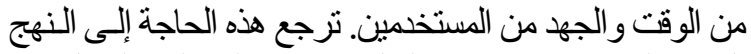

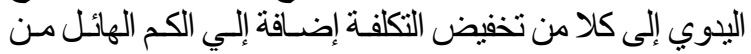
الييانات المطلوب إدارتها ، و الصعوبات و التحليات في إعادة بناء

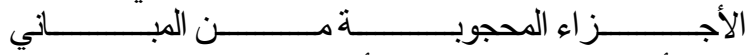

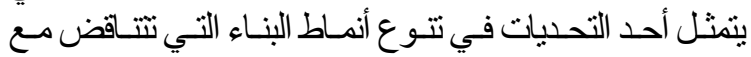

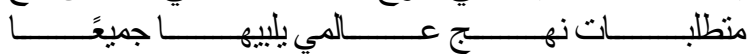

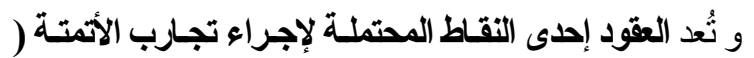

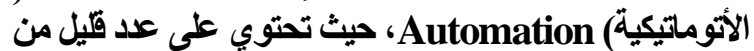

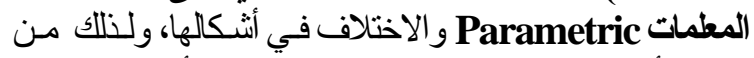

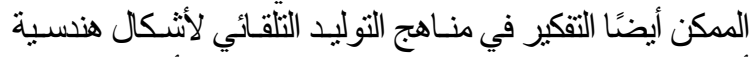

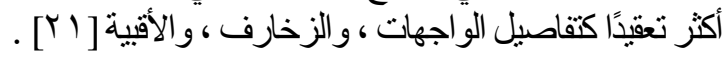

\section{من الرفع المساحي إلي النمذجة}

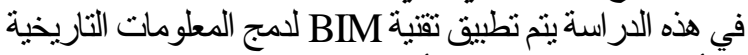
والأشكال الهنسية ثلاثية الأبعاد بطرق تعاونية بين العساملين في

\footnotetext{
شكل :- 9 الرفع المساحي بأدوات القياس التقليدية لأحد العقود المدببة
}

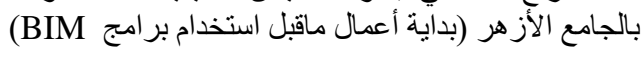

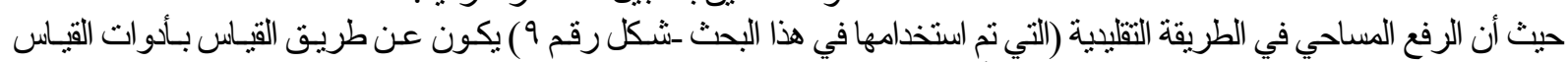

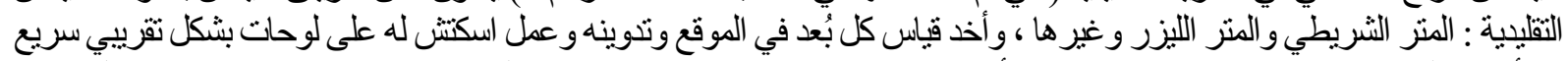

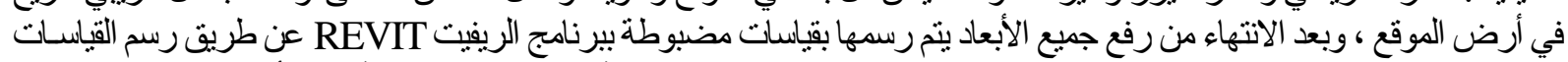

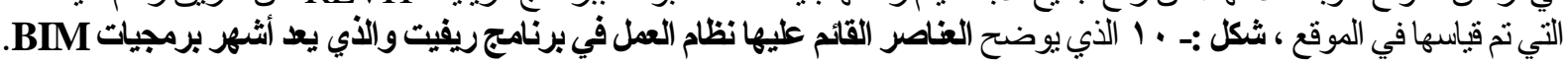

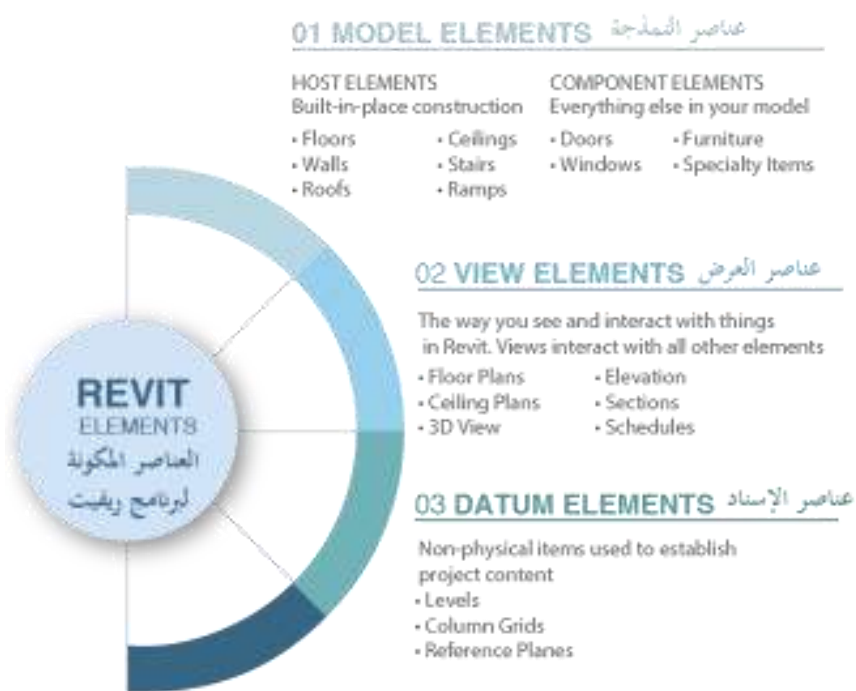

04 VIEW-SPECIFIC ELEMENTS عناهبر البري الخدية

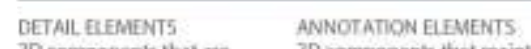
20 components that ose 20 components that maintsin real world scale a ieprosent sasto on paper's are ondy real elemsents, bita art anly vishle in ore vitu visible in one view

- Floon - Ceatrigs + Hoofs -Dirrensions - Loaded Tags

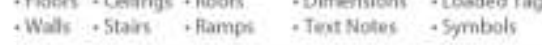

Revit شكل :- · م 1 توضيح العناصر القائم عليها برنامج
وجلير بالذكر أنه يوجد طريقة حيثة للرفع المسـاحي بدقة

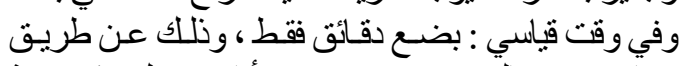

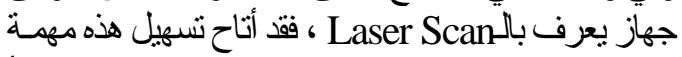

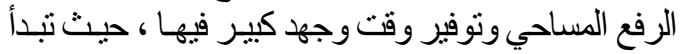

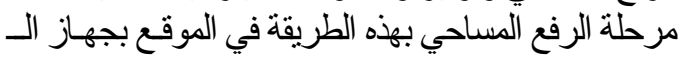
Laser Scan

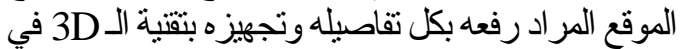

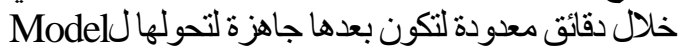
بلقة بجميع معلوماتها اللقيقة وعمل طبقات البناء و التتطبيب

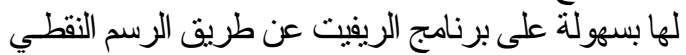

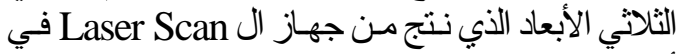

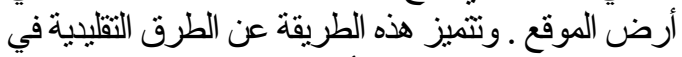
القياس و الرفع بعدة مميز ات أنيز أهمها :-

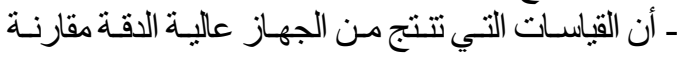
بطرق القياس النقلينية. ـ توفر هذه الطريقةوقت الرفع المساحي لكل قياسات أبعاد

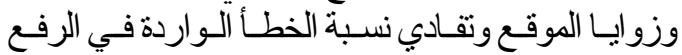
المساحي البشري. - نوفر هذه الطريقة الجها من ناحيتين : الأولى في الرفع

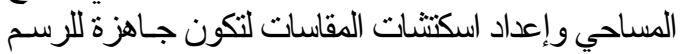




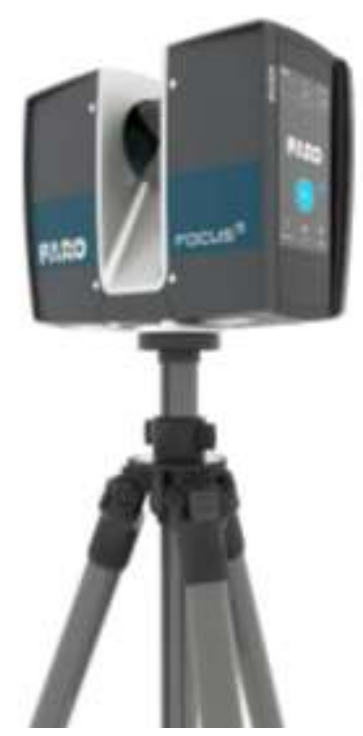

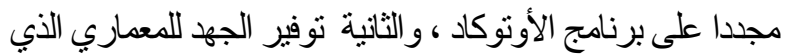

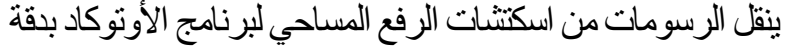

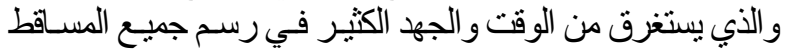

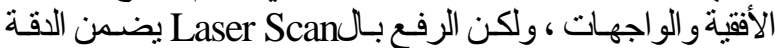

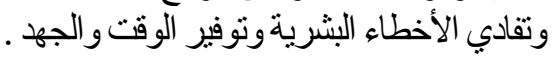

ومع تلك الميزات لهذه الطريقة إلا أنه تم استخدام الطريقـة التقليبيـة

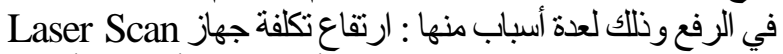

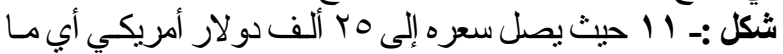

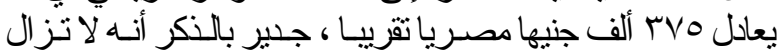

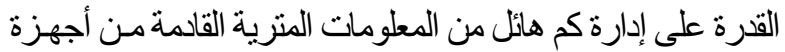

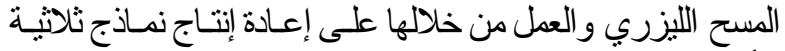

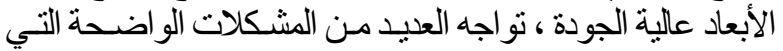

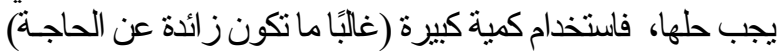

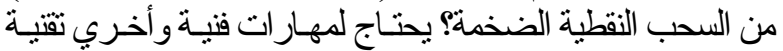
(إمكانيات الحاسوب) تحتاج الي اعداد مسبق من أجل اخر اج جيل

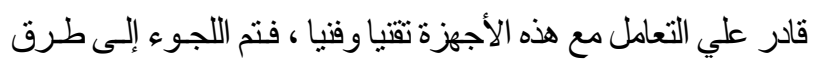

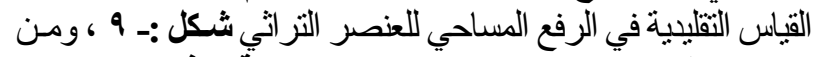

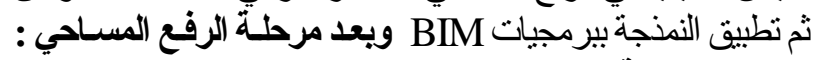

شكل :- FARO FOCUS M70 11 أحد أجهزة الليزر المستخدمة في أعمال BIM

بأت مرحلة النمذجة البار امترية للعقد المدبب والتي تمت عن طريق الخطوات التالية :-

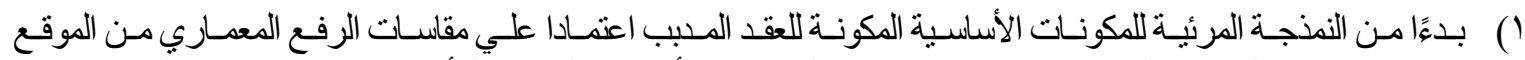

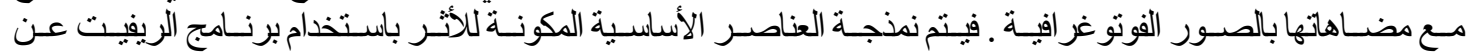

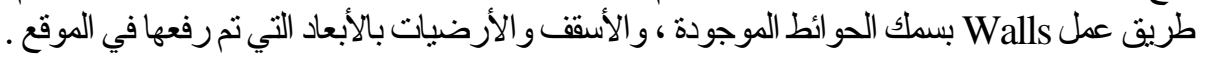

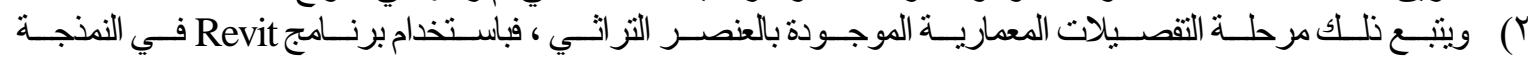

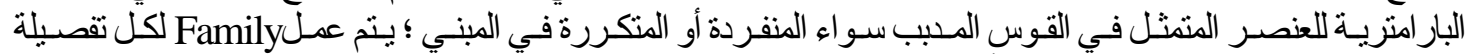

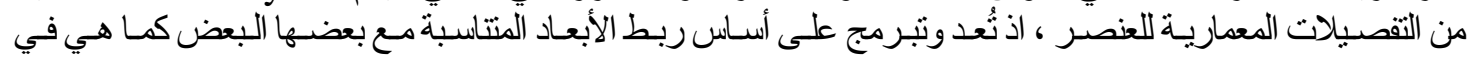

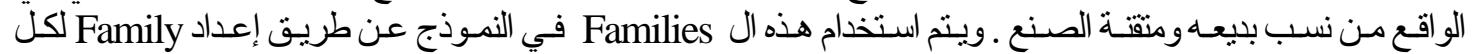
عنصر من عناصر المبنى التراثي ، بأبعاده التي تم الحصول عليها من الرفع المساحي مسبقا .
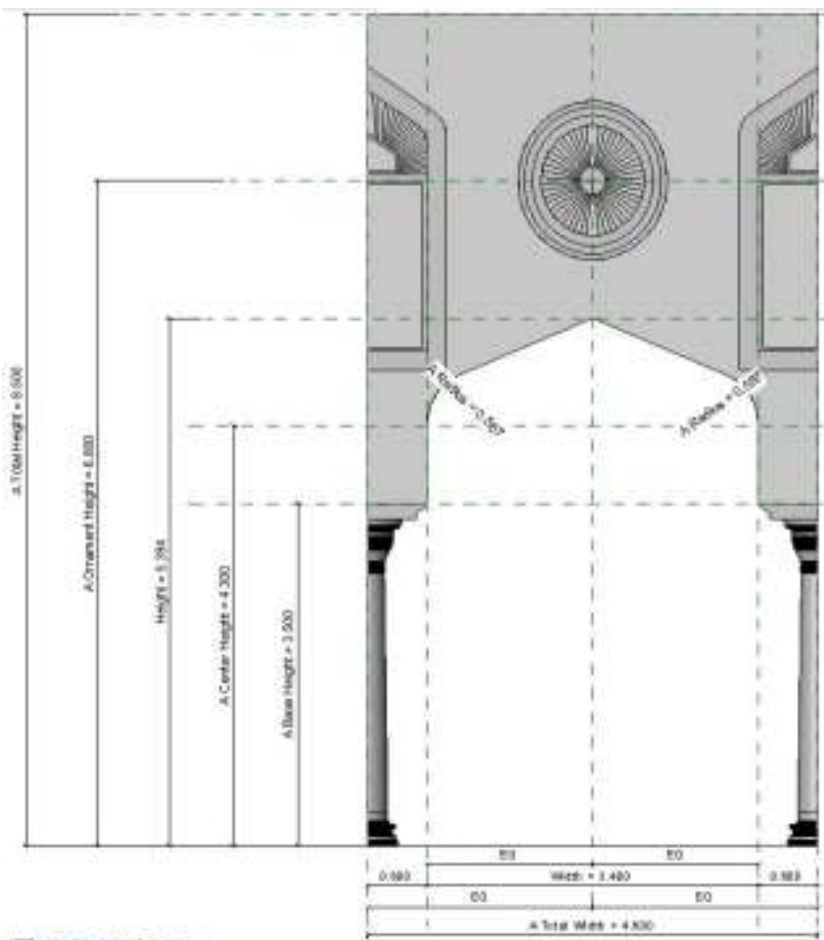

ومعماريا وليست مجرد Model ونلك حفاظـا على تناريخ نلك
من النمذجة إلي إضافة المعلومات

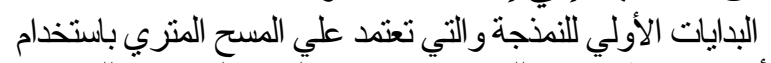

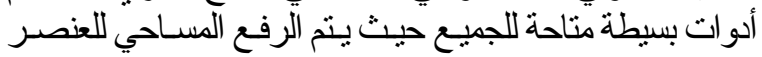

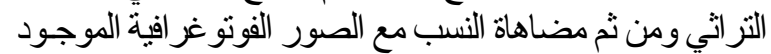

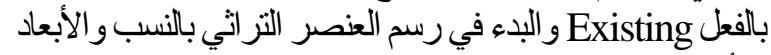

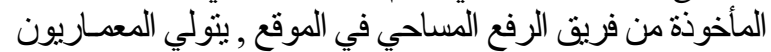

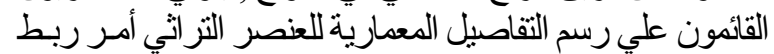

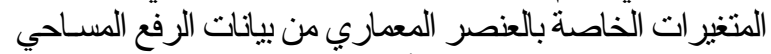

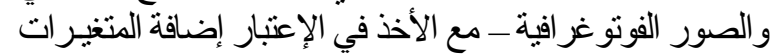

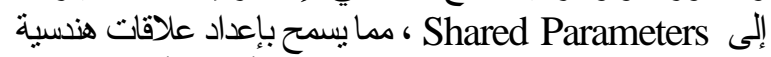

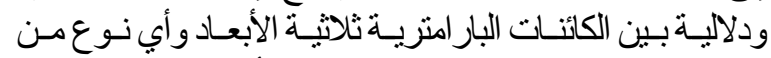

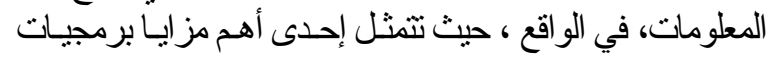
فIM r النراثخ في

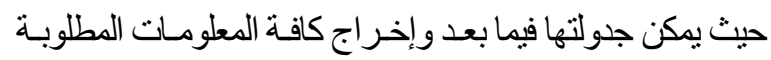

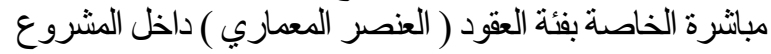

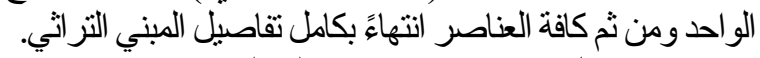
ويمكن توثيق كل family بجميع تفاصيلها التي ير ادنوتثقيقها تر اثثيا

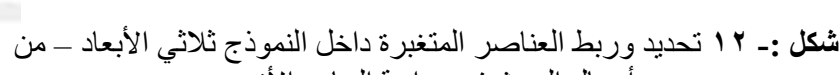 أعمال البحث في دراسة الجامع الأزهر داخل




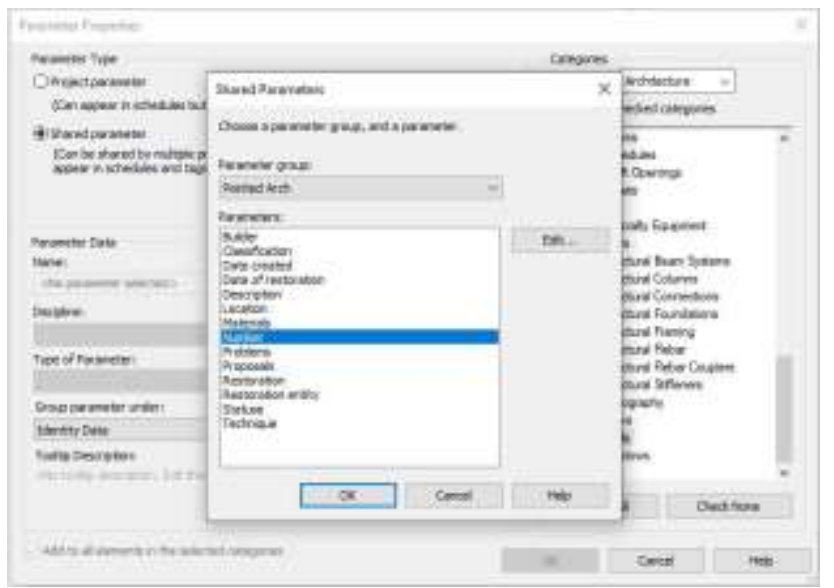

العنصر ونو اريخ الترميمات التي طرأت عليه على مـر العصبور

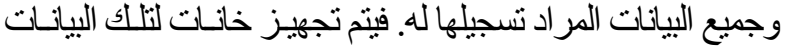

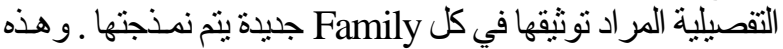

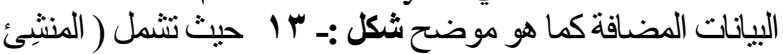

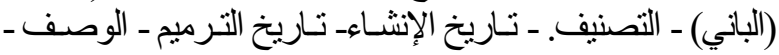

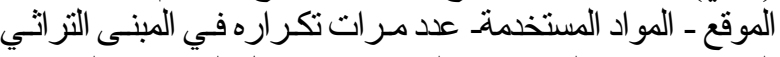

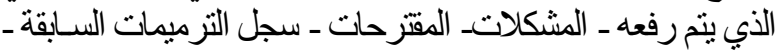

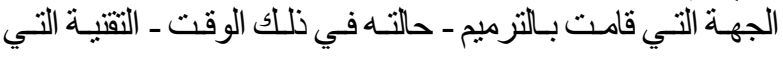
استخلمت في ترميمه.

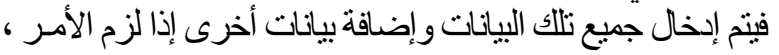

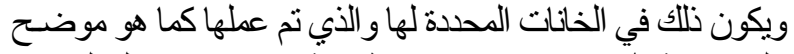

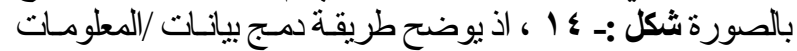

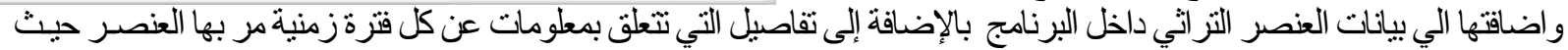

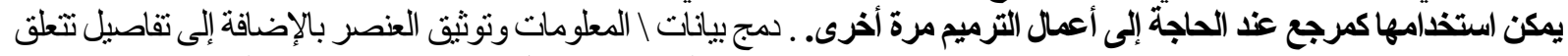

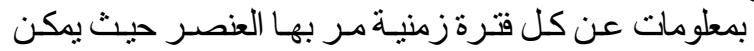

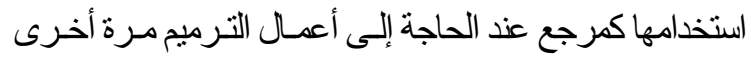

$$
\text { و الموضح في شكل :- ؛ } 1 .
$$

فـالغرض الرئيسي مـن استخدام تقتيـة BIM هـو المنهجيـة

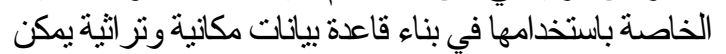

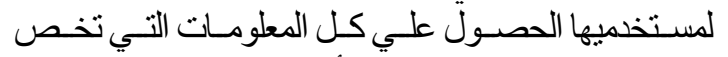

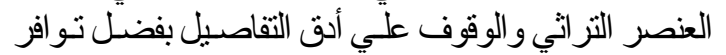

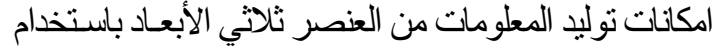

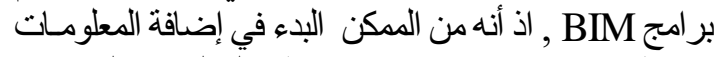

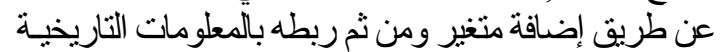

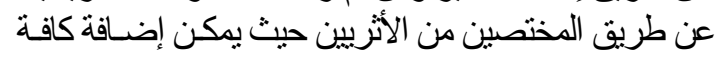

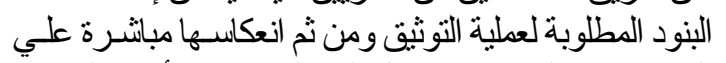

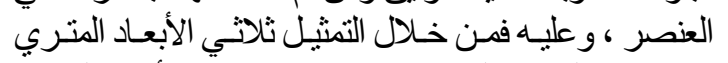

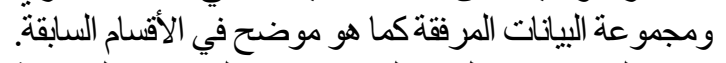

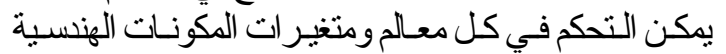

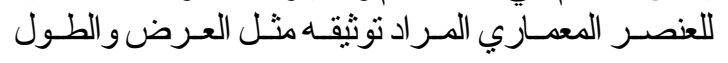

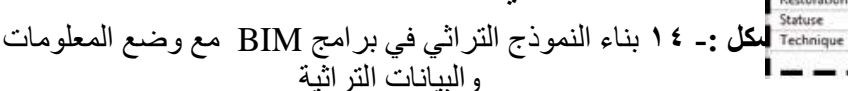

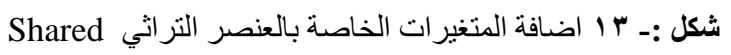

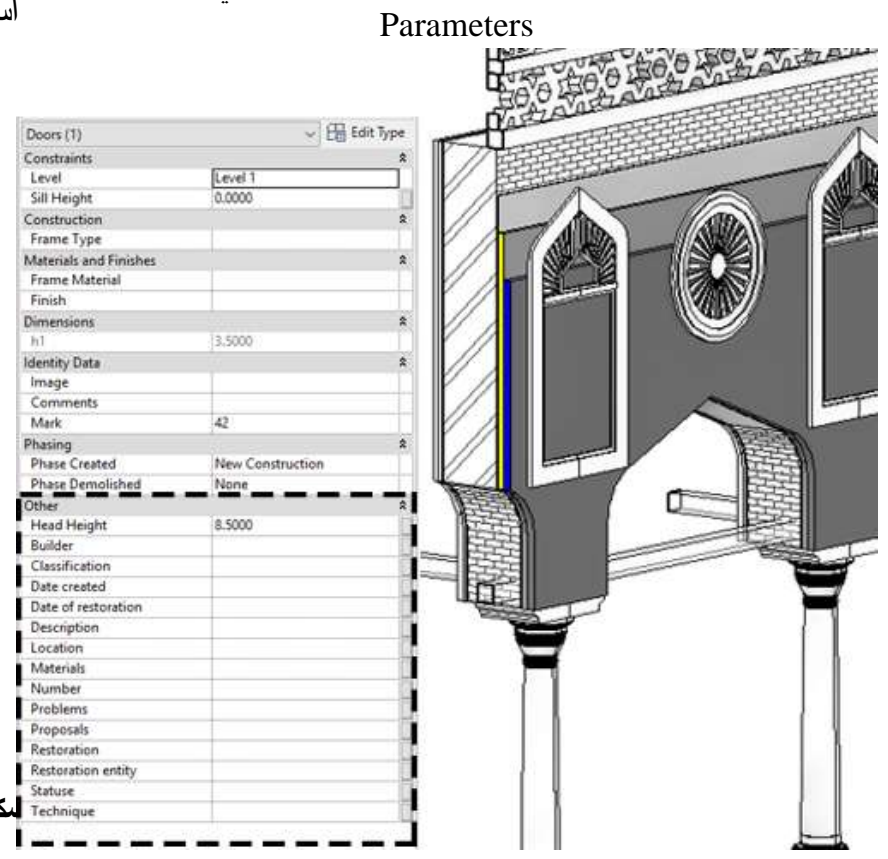

و السمك وفقًا لظروف محلدة فقطكما يمكن إجر اء هذه التعديلات على المكون بأكمله أو فقط على جز ع محدد من مكوناته الفر عية التحنية

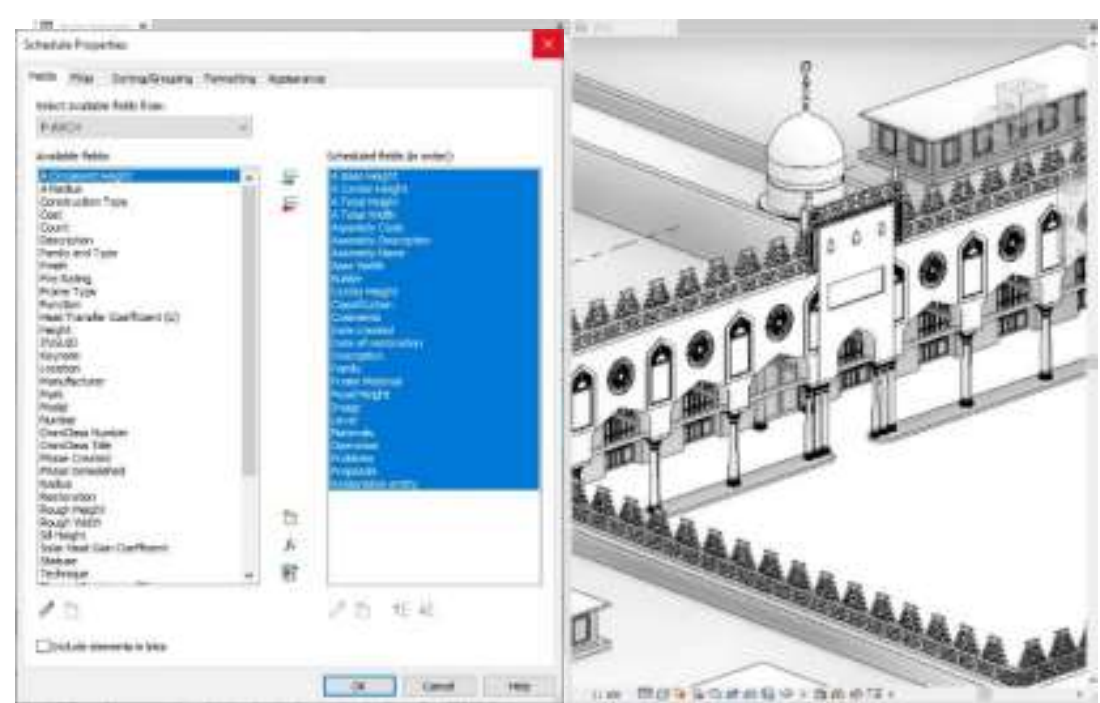

شكل :- 10 التر ابط بين العنصر ومعلوماته التر اثية في بر امج BIM

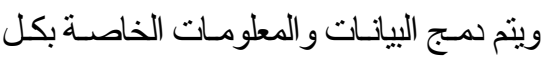
عنصر في المبنى ؛ يمكن بحد نللك إنثاء تقرير

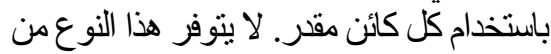

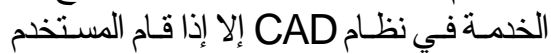

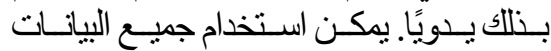
الأصلية الموجودة في نظام BIM لإنتاج العليد العيد

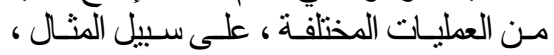

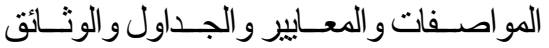

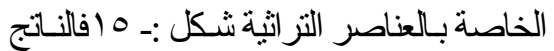

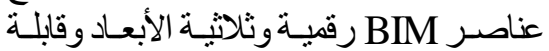

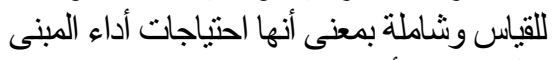

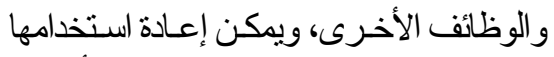

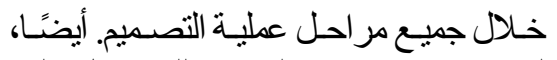
لتكون بمثابـة مصدر المعرفـة للحصول على لئى 
معلومات حول العنصر المعماري بشكل موثق ومر اجع من قبل العاملين عليه.

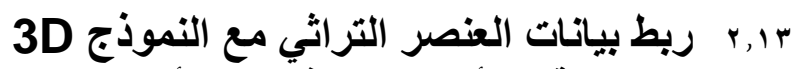

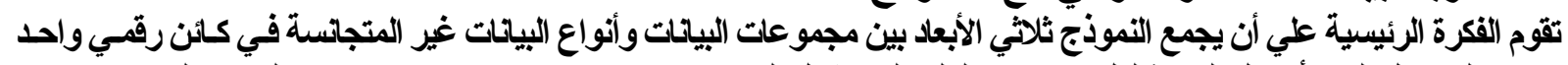

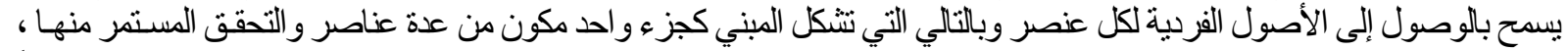

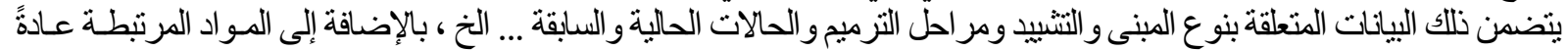

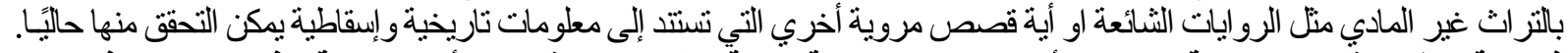

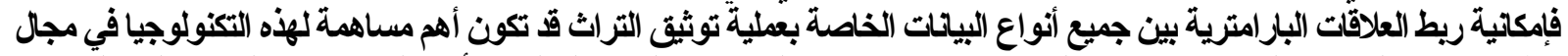

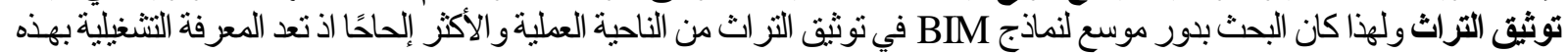

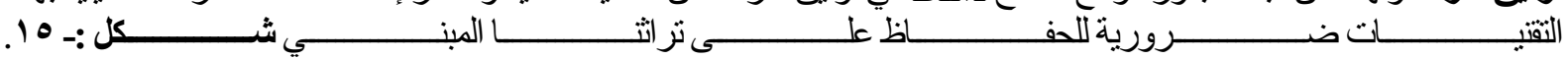

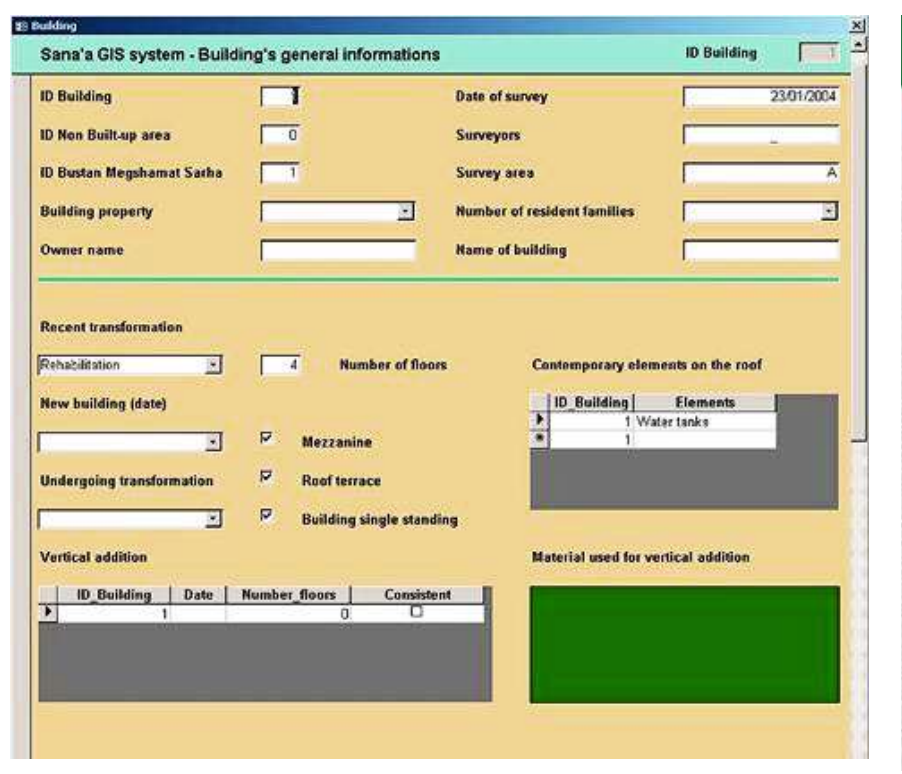

شكل :- 17 اضافة المعلومات الخاصة بالعنصر التراثي من قبل الأثريين علي

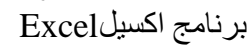

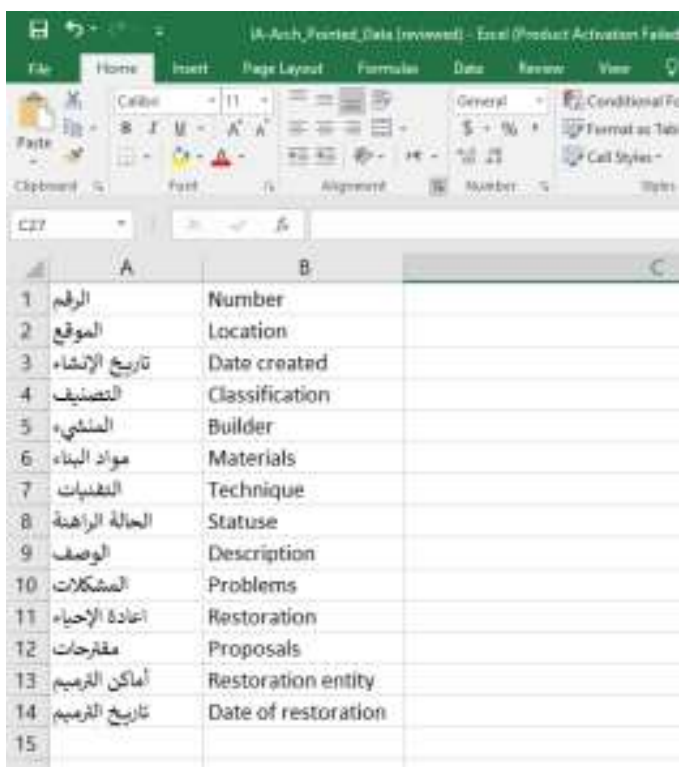

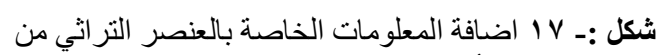

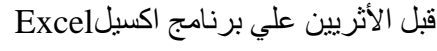

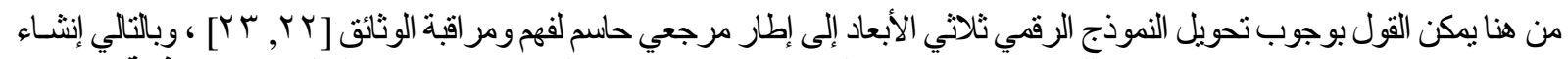

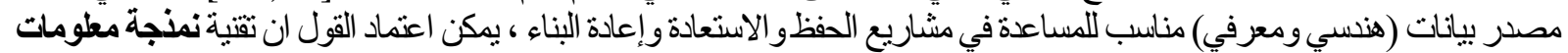

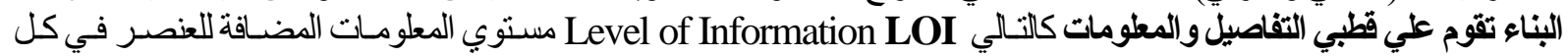

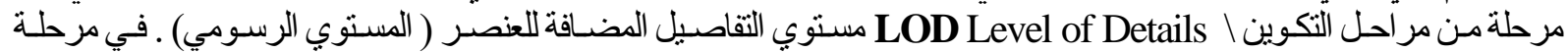

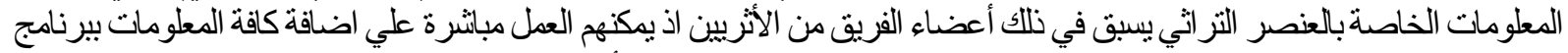

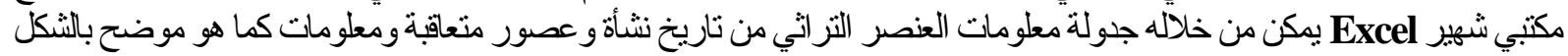

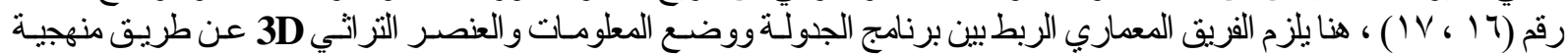

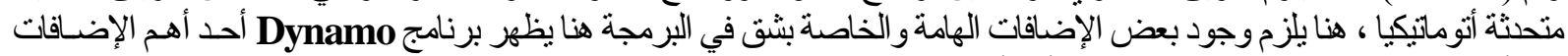

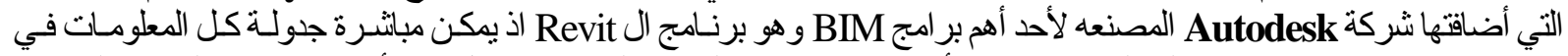

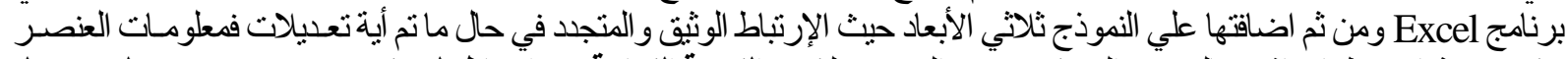

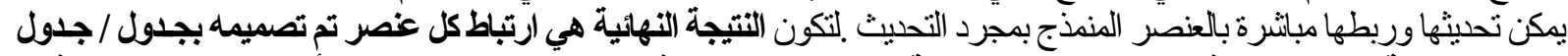

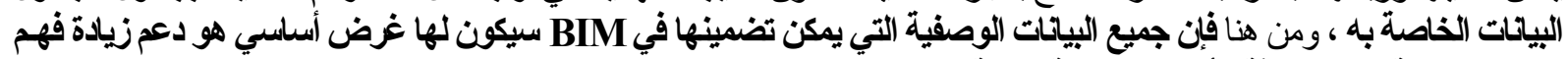

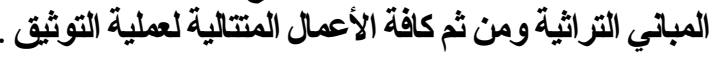

\section{Dynamo تحسين ادارة بيانات التوثيق مع دينامو}

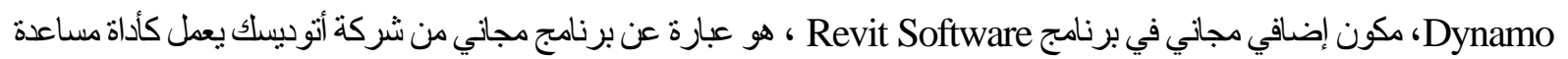

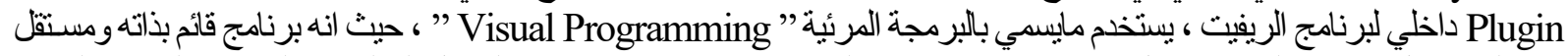

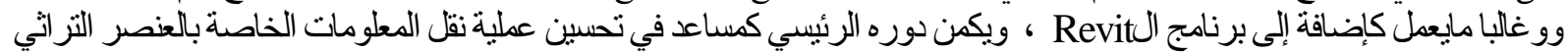

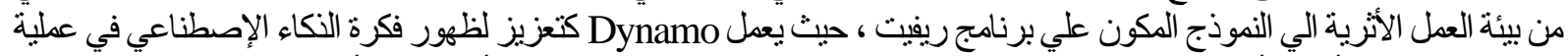

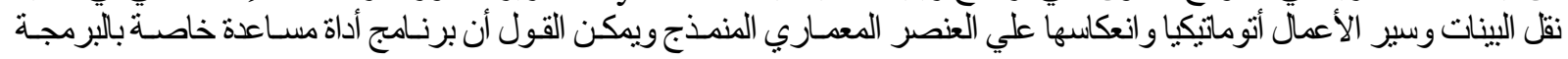


المرئية التي يمكن أن تسمح للمهنسين المعماربين و الإثريين بإنشاء نمـاذج بار امتريـة مـن خـلال تحليل بيانـات العنصـر التراتشي وربطها مباثرة بير امج النمذجة ثناثية الأبعاد أثناء النمذجة.
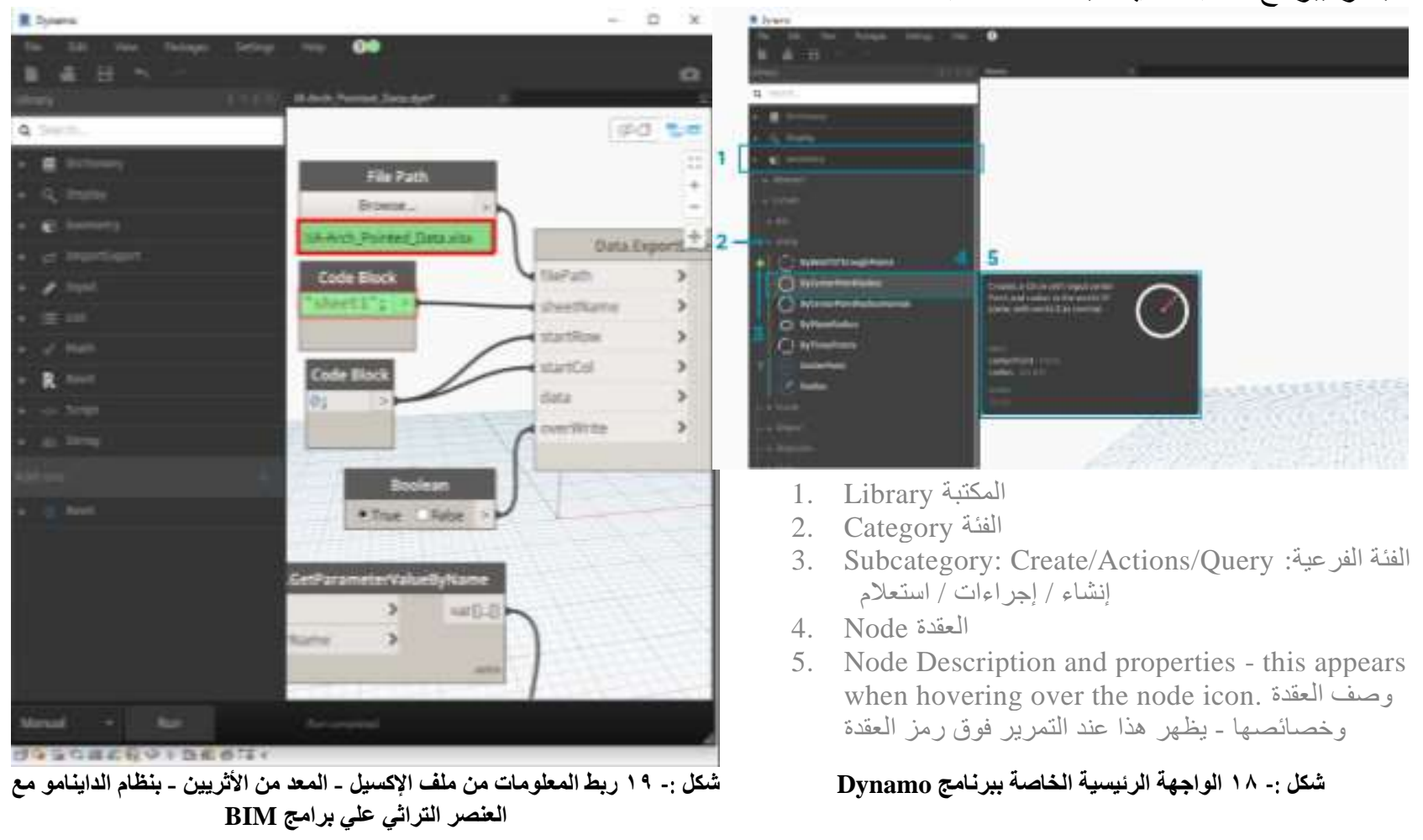

Dynamo شكل :- 11 الواجهة الرئيسية الخاصة ببرنامج

Nodes استخدام العقد في دينامو.

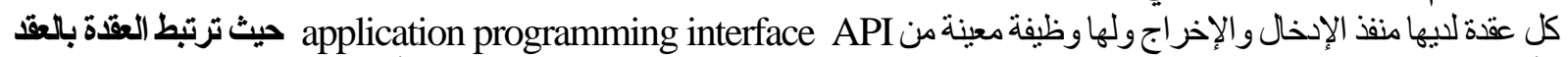

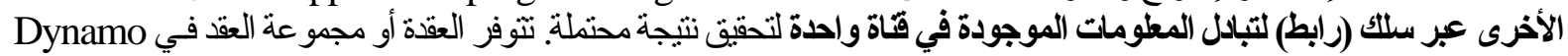

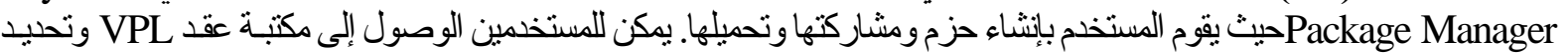

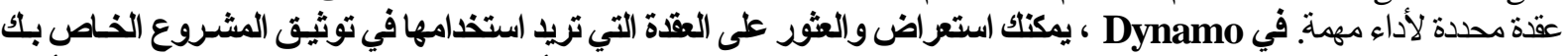

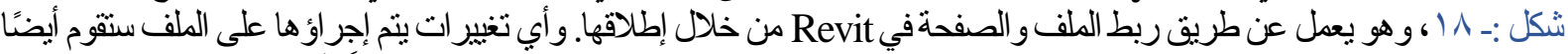

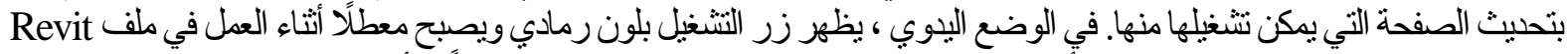

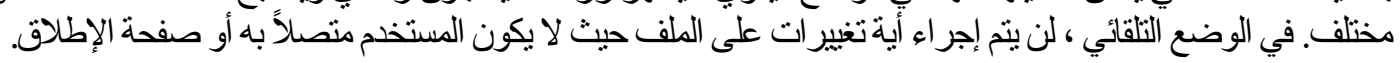

\section{مميزات استخدام Dynamo في عملية التوثيق}

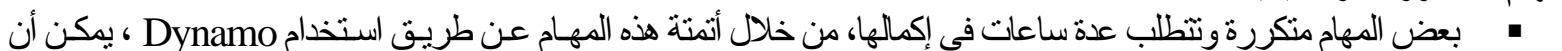

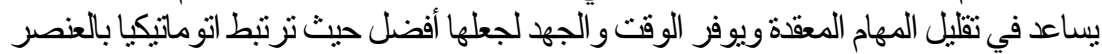

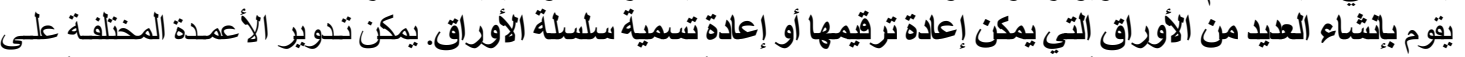

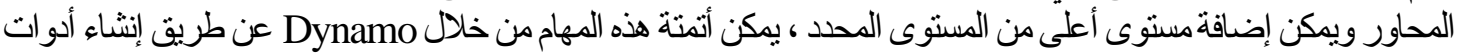

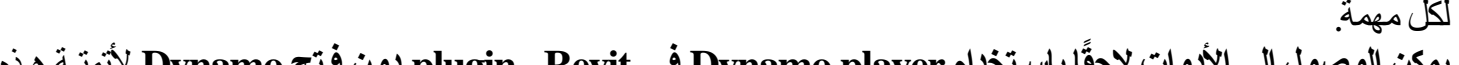

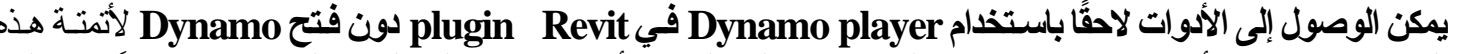

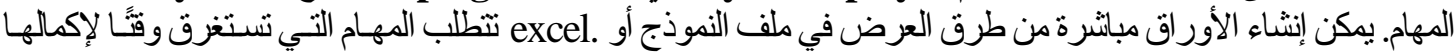

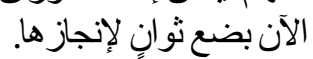

إدارج البيانات إلي المفرد المعماري باستخدام Dynamo

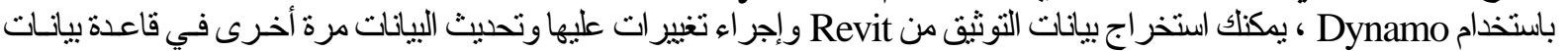

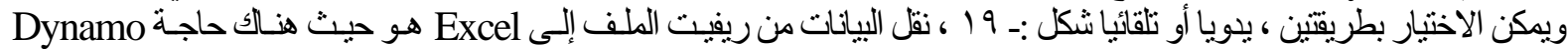

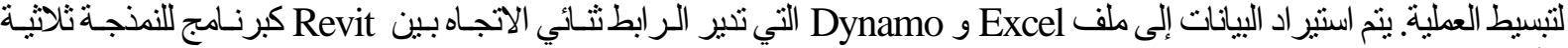
الأبعادو . Access \Excel كبر امج اضاقية تختص باضافة البيانات التناريخية ( الوصفية \المعلوماتية ) للعنصر التراثي والئية الموضح بشكل 
$\left(1 V_{6}, 17\right)$

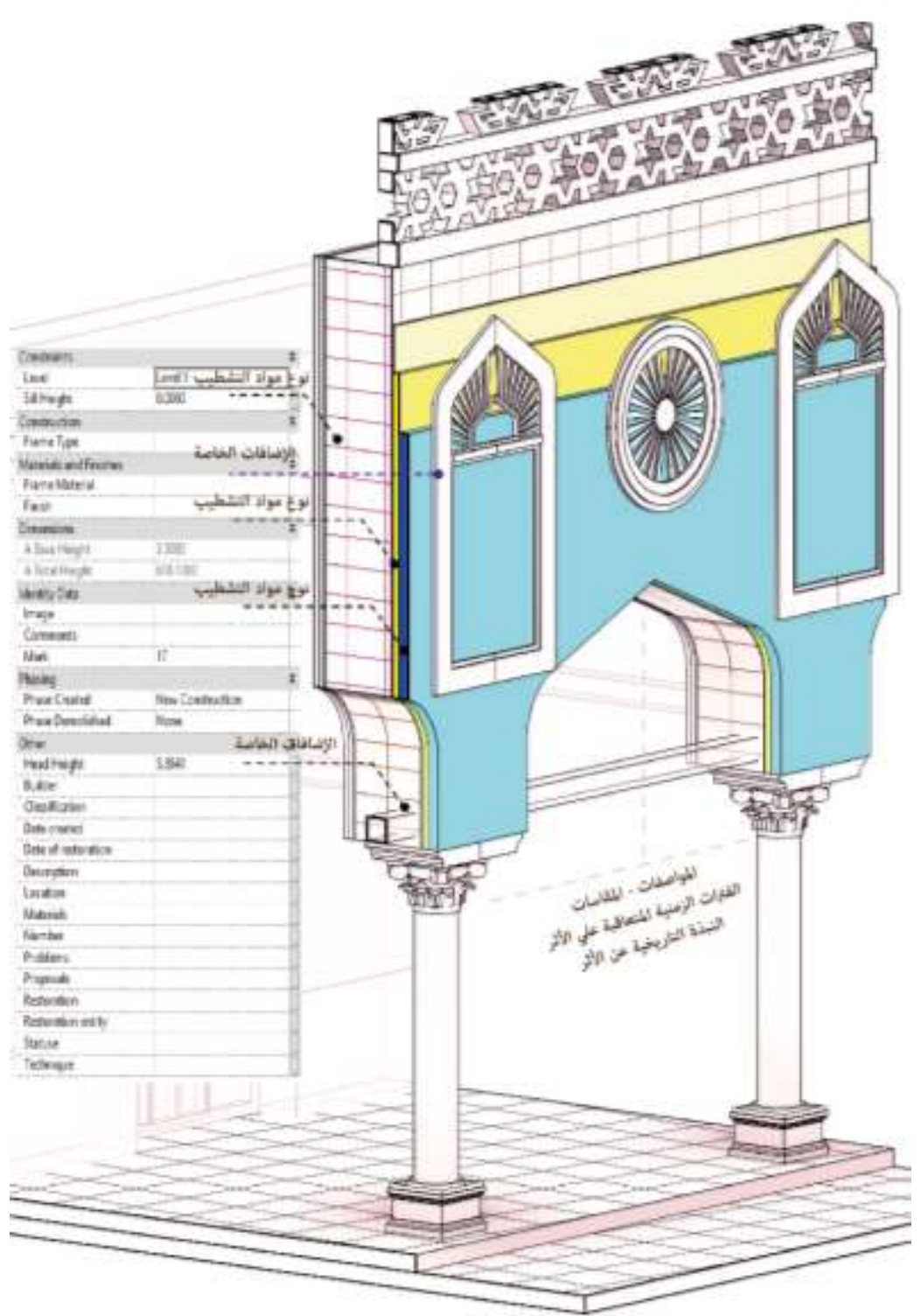

الحصول علي المفرد المعماري

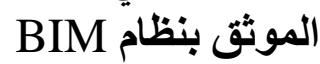

ان تطوير قاعدة بيانسات مركزيـة BIM كـأداة التوثيق التراث وحفظه ونشـره و المجهود المبنول

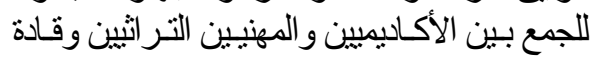

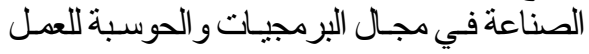

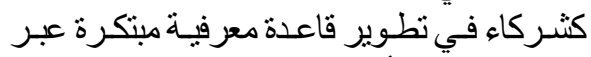

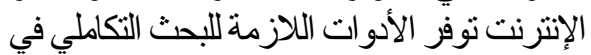

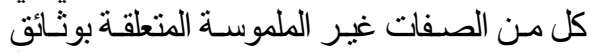

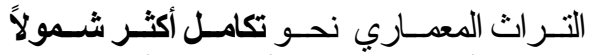
وديناميكية لليياتات المعرفية و النوعية مـن خـلال

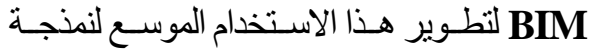

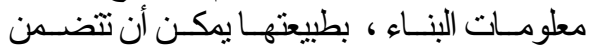
BIM و المادية والتتشغيلية. على عكس الأسـاليب الحاليـة الئية

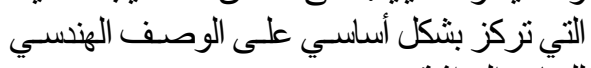

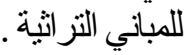

يشتمل تاريخ العمارة الإسلامية على قدر كبير من

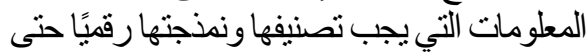

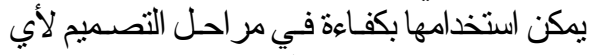

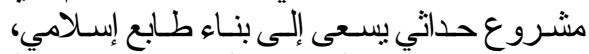

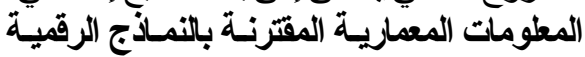

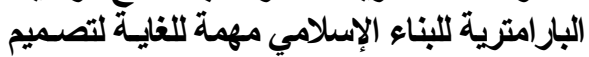
مشروع معاصر من الأنماط الإسلامية.

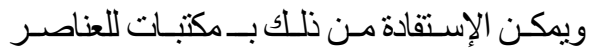

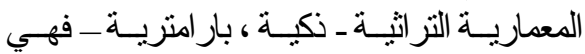

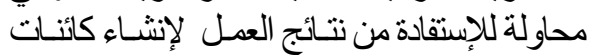

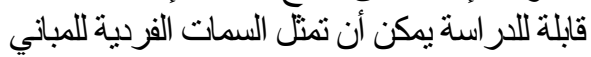
التاريخية. كما تعتبر طييعتها البار امترية ذات فات فائدة التاني

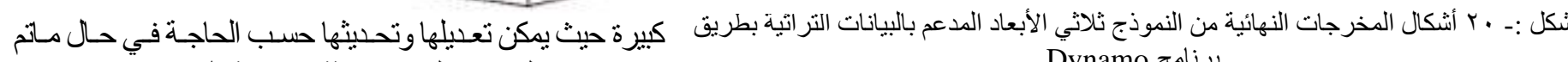

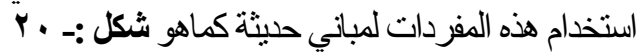
Dynamo برنامج النوذج

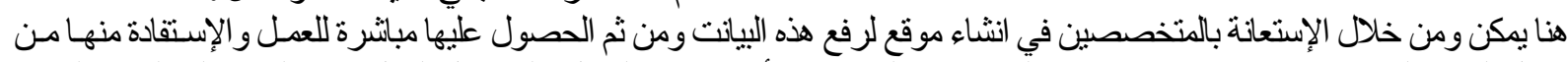

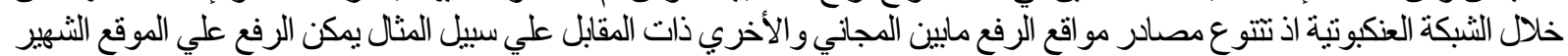
Mediafire

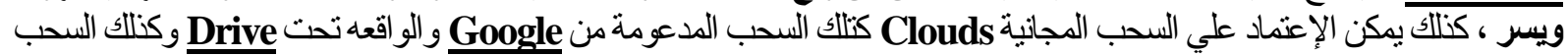

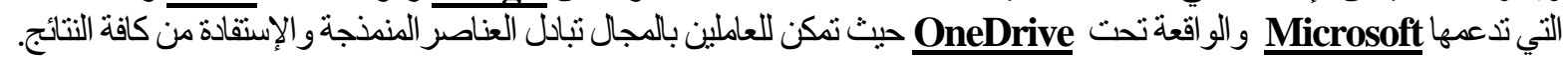

\section{النتائج العامة للبحث}

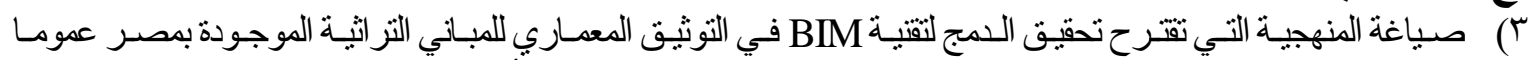

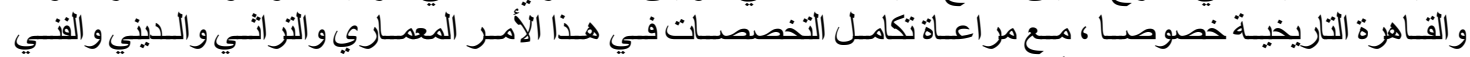

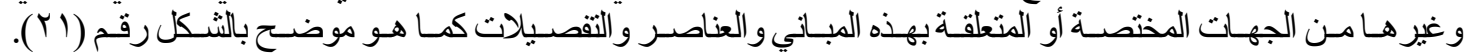

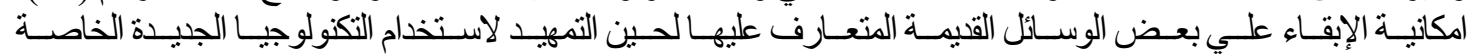

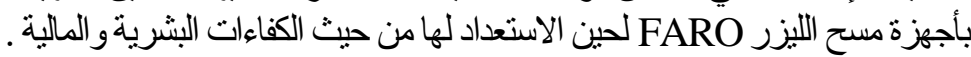

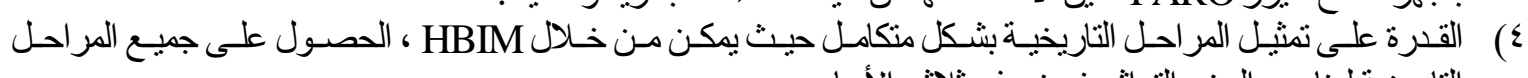
التاريخية لعناصر المبني التراثي في نموذج ثلاثي الأبعاد . 


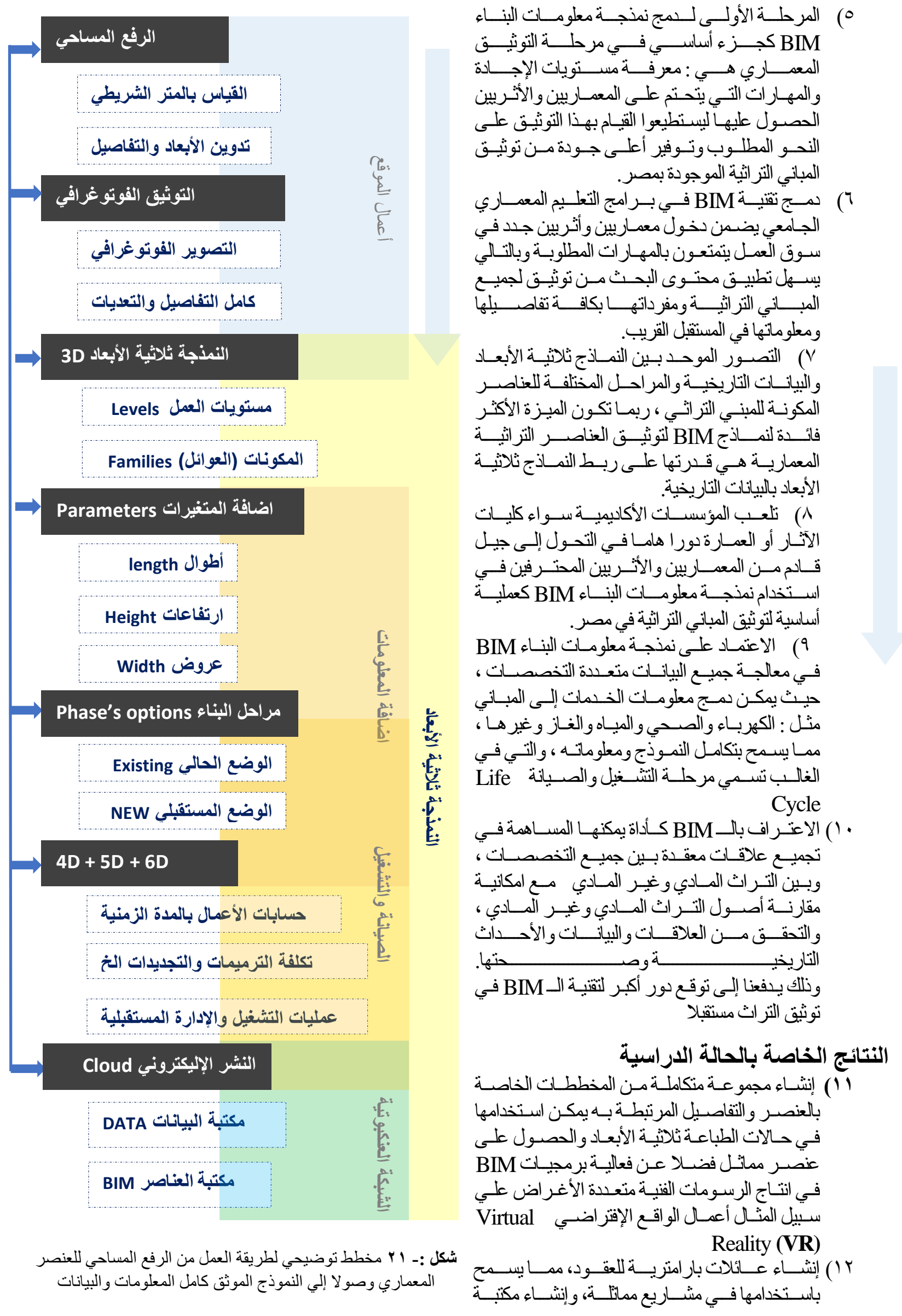




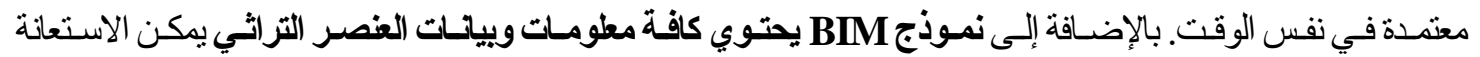
بها علي حسب المر احل التتموية للعنصر التزاثي المختلفة في كامل دورة حياة المبني التزاني.

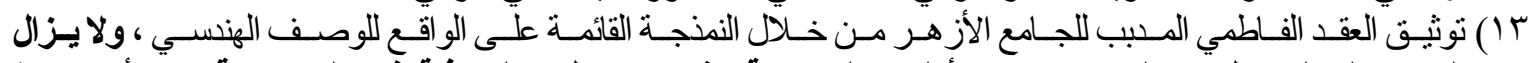

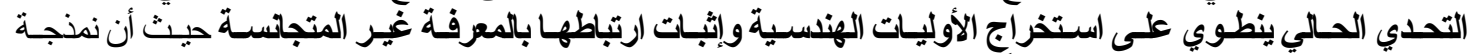

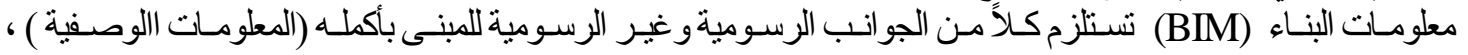

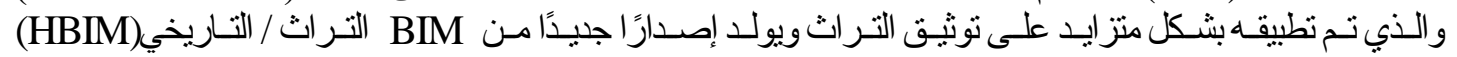
Heritage/Historic

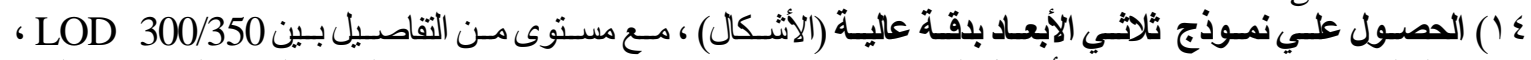

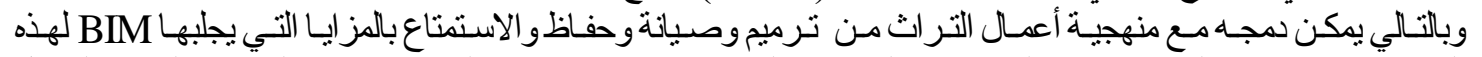

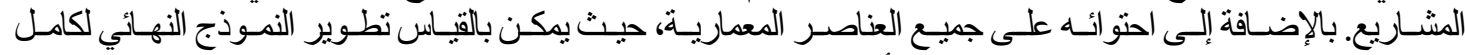

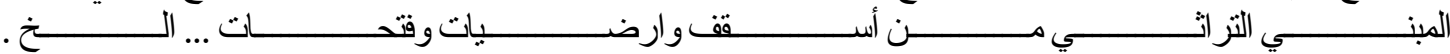

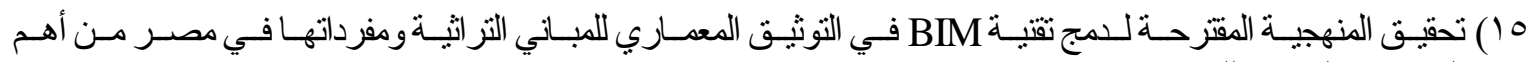
التوصيات الرئيسية للبحث.

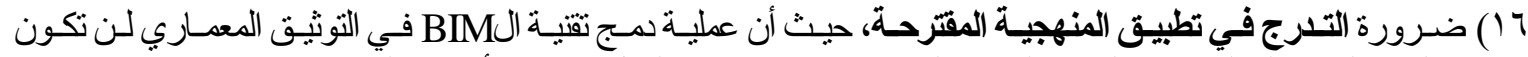

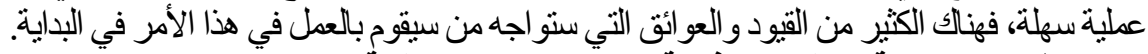

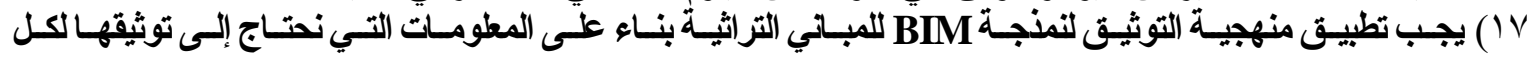

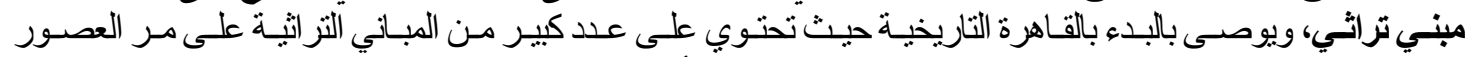

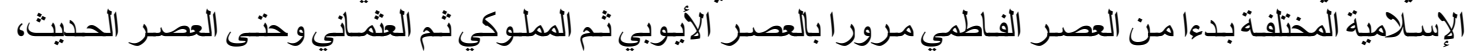

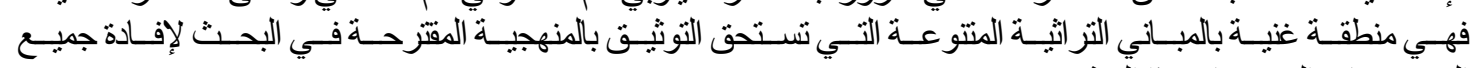
التخصصات التي تحتاج هذا التونيق.

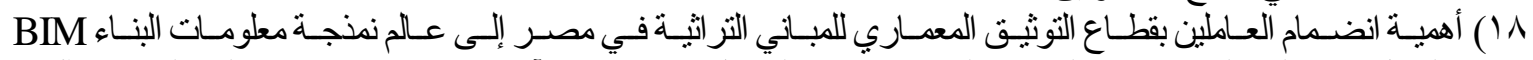

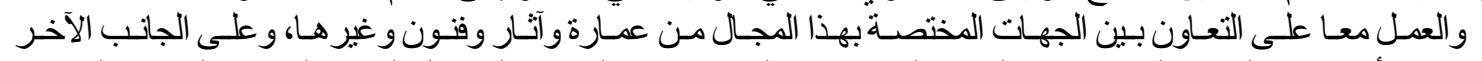

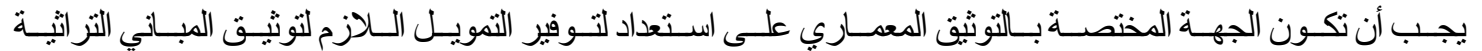

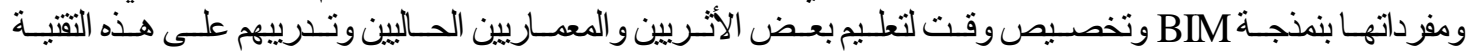
لمو اكبة التوثيق بالطريقة المطروحة في البحث.

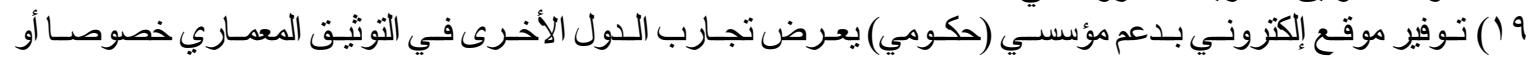

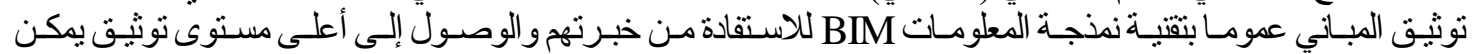

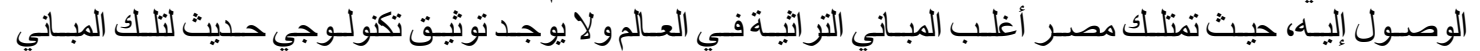
التزراثية.

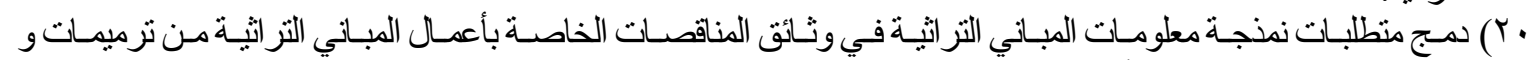

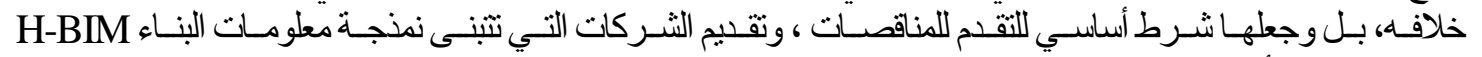

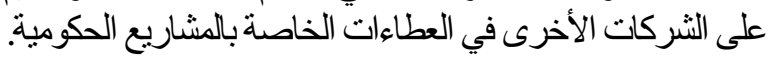

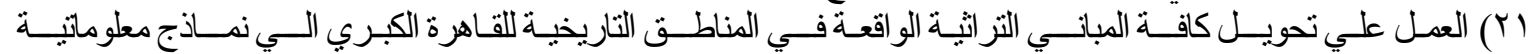

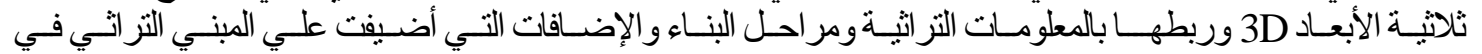

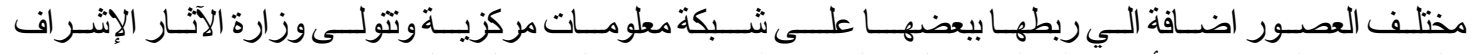

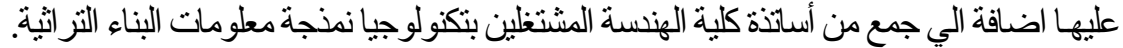

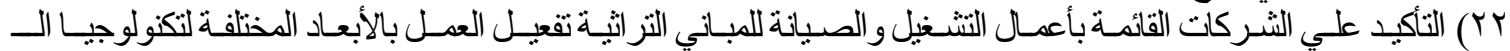

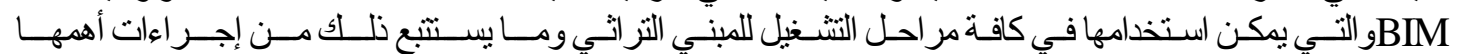

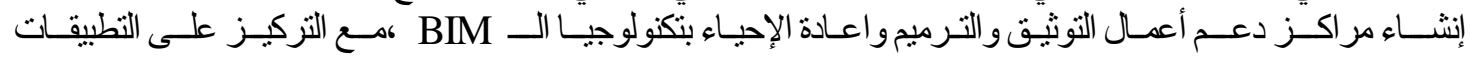

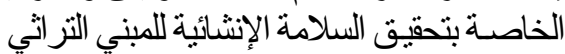

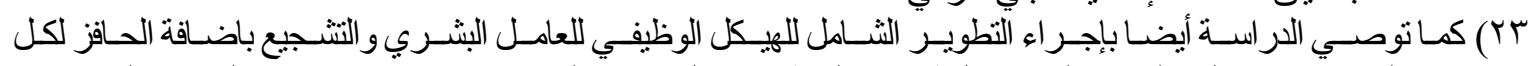

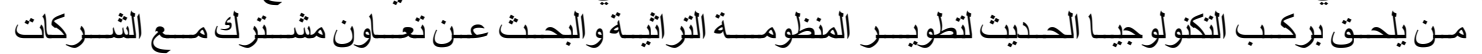

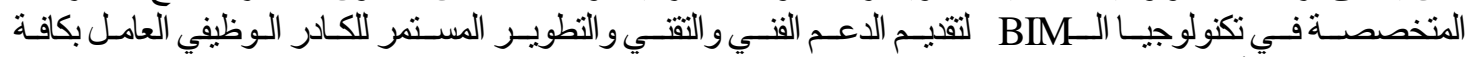
القطاعات المهنمة بأعمال تونيق التزاث المعماري 
1. Djibril, M, Hadi, Y, Haj Thami, R (2006). Fundamental region based indexing and classification of islamic star pattern images. In: ICIAR'06 Proceedings of the Third international conference on Image Analysis and Recognition, Volume Part II, (pp. 11).

2. Okamura, T, Fukami, N, Robert, C, Andres, F (2007). Digital resource semantic management of islamic buildings case study on Isfahan islamic architecture digital collection. International Journal of Architectural Computing, 5(Number 2 / June 2007).

3. Muir, E, \& O'Neill, R (1994). The paperless design studio. [Online] Available at: https://www.arch.columbia.edu/DDL/paperless/NEWSLINE.html [Accessed 22 September 2015]

4. Denis, F (2015). Building Information Modelling - Belgian Guide for the construction Industry. 2015 ed. s.l.: Brussel: ADEB-VBA.

5. Baik A, Alitany A, Boehm J, Robson S (2014) Jeddah historical building information modeling "JHBIM". ISPRS Technical Commission V Symposium, Riva del Garda, pp 41-47

6. Webster's Dictionary

7. Charter On The Protection And Management Of Underwater Cultural Heritage (1996)

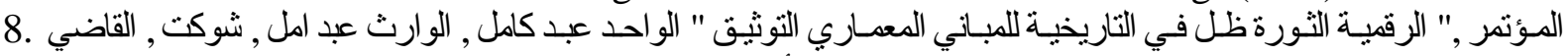

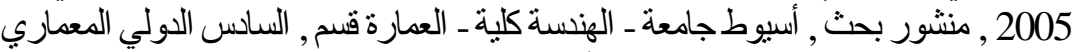

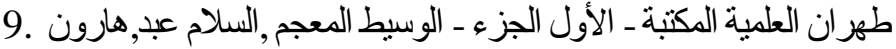

10. AGC. The Contractors' Guide to BIM. 1st ed., Associated General Contractors of America, 2006, p 41

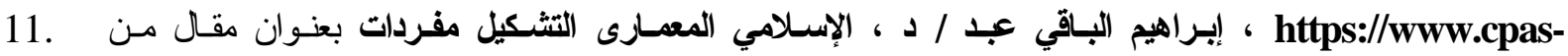

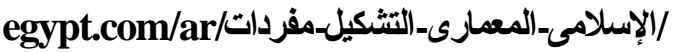

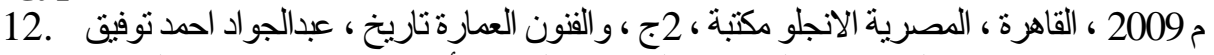

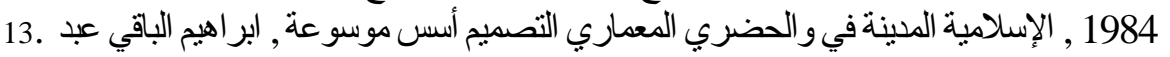

14. Creswell, K.A.C,early Muslim Architecture, Vol.1, -James, Allan, Ltd, London, 1968

15. المصريون الباحثُون Www.egyres.com

16. Murphy, M.; McGovern, E.; Pavia, S. Historic Building Information Modelling-Adding intelligence to laser and image based surveys of European classical architecture. ISPRS J. Photogramm.

Remote Sens. 76,89-102.

17. Castellano-Romun, M.; Pinto, F. Dimensions and Levels of Knowledge in Heritage Building Information Modelling, HBIM: The model of the Charterhouse of Jerez (CJdiz, Spain). Digit. Appl. Archaeol. Cult. Herit. 2019, 14, e00110.

18. Antonopoulou, S.; Bryan, P. BIM for Heritage: Developing a Historic Building Information Model; Historic

England: Swindon, UK, 2017

19. Brumana, R.; Della Torre, S.; Previtali, M.; Barazzetti, L.; Cantini, L.; Oreni, D.; Banfi, F. Generative HBIM modelling to embody complexity (LOD, LOG, LOA, LOI)

20. Murphy, M., McGovern, E., Pavia, S., 2009. Historic building information modelling (HBIM). Struct. Surv. 27, 311-327.

21. Rodrsguez-Moreno, C.; Reinoso-Gordo, J.F.; Rivas-Lopez, E.; Gmez-Blanco, A.; Ariza-López, F.J.; Ariza-Lepez, I. From point cloud to BIM: An integrated workflow for documentation, research and modelling of architectural heritage. Surv. Rev. 2016, 50, 212-231.

22. Letellier, R.; Eppich, R. (Eds.) Recording, Documentation and Information Management for the Conservation of Heritage Places; Routledge: Abingdon, UK, 2015.

23. Johansson, M.; Roupé, M.; Bosch-Sijtsema, P. Real-time visualization of building information models (BIM). Autom. Constr. 2015, 54, 69-82. 